\title{
Technical Efficiency of Smallholder Wheat Producers in Simada District of Amhara region, Ethiopia
}

\author{
Aderajew Gebrie $^{1}$ Dr, Melkamu Mada ${ }^{2}$ \\ 1.Wolikite University, Department of Agricultural Economics, P.O.Box 07, Ethiopa \\ 2.Arba Minch University, Department of Economics, P.O.Box21, Ethiopia
}

\begin{abstract}
Wheat (Triticum aestivum) is one of the major staple cereal crops in Ethiopia. High productivity and efficiency in its production is critical to improve food security, reduce the level of poverty and achieve agricultural growth. Therefore, the objective of study was to measure the level of technical efficiency of wheat producers and to identify factors that contribute for efficiency differences among smallholder farmers in the study area. The study was based on cross-sectional data collected from 154 wheat producer farmers by multi- stag sampling technique during 2017/18 production season. Technical efficiency of sampled farmer in wheat production was estimated by CobbDouglas functional form in stochastic frontier model (SFM) with single stage estimation method. The estimated SFM indicated that land, labor and seed were significantly and positively influence wheat production at 1 percent of significant level. However, urea was negatively influence wheat production at 10 percent of significant level. Production function in wheat production existed in increasing return to scale (1.22). The estimated gamma $(\gamma)$ parameter was about 0.29 .It indicated that the relative deviations of actual output from the frontier output due to inefficiency. The estimated mean level of TE of wheat producers was 0.79 . From specific socioeconomic and institutional factors hypothesized that influence technical efficiency of farmers in wheat production, credit access and frequency of extension contact were significantly and positively influence the level of technical efficiency in wheat production at 10 percent of significance level. Education level was significantly and negatively influences the level of technical efficiency in wheat production at 10 percent of significance level. Raw sowing and frequency of plowing were significantly and negatively influence the level of technical efficiency in wheat production at 5 and 1 percent of significance level, respectively. Therefore, the study suggested the above mentioned significant variables have important for policy implications in that development programs may give fruitful attention so as to mitigate the existing level of inefficiency of farmers in the production of wheat in study area.
\end{abstract}

Keywords: Technical Efficiency, Stochastic Frontier Model, Single Stage Estimation, Ethiopia

DOI: $10.7176 / \mathrm{DCS} / 10-1-01$

Publication date: January $31^{\text {st }} 2020$

\section{INTRODUCTION}

Agricultural is the main Pillars' of Ethiopian economy contributing about 36.2 percent to the GDP and 72.7 percent to national export earnings. It also supplies available industrial raw materials while employing about 85 percent of the population (CIA, 2016). Nearly all agricultural holders attain the food they consume and the money they require to cover expenditures from farming activities (CSA, 2016).

Within the category of grain crops, cereals are the major food crops both in terms of the area they are planted and volume of production obtained. They are produced in larger volume compared with other crops because they are the principal staple crops. Five key cereals (teff, wheat, maize, sorghum and barley) are the core of Ethiopia's agriculture and food economy. Approximately 98 percent of cereals are produced by smallholder farmers and remaining two percent are produced by trader farmers mainly for seed purposes (Abu, 2014).

Despite the area cereals are planted, yields are low and overall production is highly vulnerable to weather shocks, particularly droughts, input price, quality of seed varieties, amount of input used, use of irrigation, fragmented nature land holding, lack sufficient farm management practice, erratic rainfall, high population growth, low and insufficient use of agricultural input contribute to low level of cereal productivity in general and wheat productivity in particular. Both raising production levels and reducing its variability are essential aspects of reducing poverty level and improving food security in Ethiopia to ensure adequate food availability and increase household income (Alemayehu et al., 2011).

In Ethiopia, increasing crop production and productivity is fundamental event for acquiring food security and providing inputs for the industrial sector. Agricultural output can be improved through increasing use of factor of production, opening of modern technologies and improving the efficiency of factor of production without new technology and by integrating these can be improve agricultural productivity (Kinde, 2005).

Wheat is one of the important cereal crops in Ethiopia, which standing in fourth level from the total cereals production 16 percent next to maize, sorghum and teff in area coverage and third level in amount of output providing .Even though, it has productivity potential, know day is not sufficient and currently there is wheat importer from other country to Ethiopia (Kaleb and Workneh, 2016).

According to CSA in 2017 agriculture plays significant role in Ethiopia to achieve economic, political and 
social stability. However, increasing population pressure with rate of 2.46percent (WPP, 2017) and low levels of agricultural productivity have been critical problems in Ethiopia. These have aggravated the food insecurity situation by widening the gap between demand and supply of food. As result Ethiopia is one of the developing countries in the world unable to meet its domestic food demand.

The presences of traditional farming techniques, inefficient use of agricultural input, poor services access such as extension, credit, marketing, infrastructure and infant agricultural policies are among the major factors that have a great extent constrained the development of Ethiopia's agricultural productivity (Arega and Rashid ,2005). As said by Abu (2014) Ethiopia remains one of the largest recipients of food aid in Africa, receiving around 27 percent of the global food aid given to sub-Saharan Africa. Due to low productivity of wheat EGTE supplies wheat for consumer before the harvest start. Only75 percent of wheat produce in Ethiopian and other 25 percent have to be imported commercially and through food aid from other country.

According to woreda-level crop production rankings in Ethiopia by international food policy research institute, Simada is one of the woreda in the Amhara Region of Ethiopia in part of the south Gondar zone, among top 25 wheat producing woreda, which is not include in ranking level due low production and productivity of wheat product (James et al.,2015).

As CSA result showed in 2017 productivity of wheat in south Gondar was $20.67 \mathrm{qt} / \mathrm{ha}$ which is less than $24.49 \mathrm{qt} / \mathrm{ha}$ as north Gonder, regional level average of $23.80 \mathrm{qt} / \mathrm{ha}$ and country level average of $26.75 \mathrm{qt} / \mathrm{ha}$, Experimental yield of wheat above $50 \mathrm{qt} / \mathrm{ha}$ (MoA, 2012) and also which is less than $24 \mathrm{qt} / \mathrm{ha}$ of wheat as Africa (FAO, 2015) and $33.9 \mathrm{qt} /$ ha of wheat as world (WAP, 2017).

FHE reported in 2017during food resource (wheat) dispatch by FHE for woreda, like Lay_Gayint, TachGayint and Simada woreda in south Gondar zone Amhara region over dispatched above plan to Simada woreda than other woreda due to food insecurity. Food aid given by FHE for PSNP beneficiaries includes; 438.74 MT of commodities to 23,092 (10,744 male and 12,348 female). This all situations shows that study area face agricultural productivity and inefficient use of agricultural input problem. Since, this gap will call attention generally for Ethiopia and particularly for study area. This problem can be mitigated by adopting improving technologies, increasing the use of improved technologies and improving the efficiency of farmers at given input and technologies. But improving the efficiency of farmers at given input is less costly than adopting and increasing improved technologies in Ethiopia and study area.

But, a few number of empirical research(Solomon,2012; Ermiyas, 2013 and Kifle,2014 ) done in Ethiopian relating to increasing agricultural productivity by improving efficiency level of cereal production through twostage estimation procedure for determinant of technical efficiency level in cereal production . However, the twostage procedure lacks consistency in assumptions about the distribution of the inefficiencies. These issues are not recognized particularly wheat production in $2017 / 18$ production period in study area through one-step estimation procedure for determinant of technical efficiency in wheat production.

Then, the results of this study will contribute to fill this gap through measure the level of technical efficiency and identify the main determinants which lead technical efficiency difference between small holder farmers in wheat production at given distinct and finally recommend results for any concerned body who need to improve level of technical efficiency in study area.

\section{RESEARCH METHDOLOGY}

\subsection{Description of Study Area}

Simada woreda is found in South Gondar Administrative Zone, Amhara Regional State. It is one of the eleven administrative woreda of South Gondar Zone. It has 40 Kebele, one town and 39 rural Kebele administrations. The seat of woreda administration is Wogeda, which is located at $105 \mathrm{~km}$ distance southeast of the zonal capital Debretabor and found at about $205 \mathrm{~km}$ distance away from the regional capital Bahir Dar and at $770 \mathrm{~km}$ distance from Addis Ababa. Simada woreda boarders in the north with Tach_Gayint and Lay _Gaint distinct, in the south

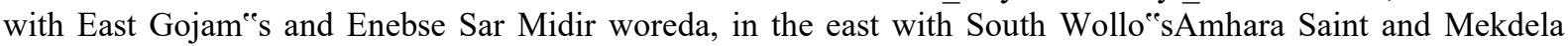
woreda and in the west with Este woreda of South Gondar Zone(SARDO, 2009).

The physiographic setting of Simada woreda manifested by valleys (10 percent), mountainous (20 percent), plateau/plain/ (20 percent), hills (40 percent) and others (10 percent). Its altitude ranges from 1500 to 4000 meters above sea level. About 11pecent, 42 percent and 47 percent of the study area is occurring in dega (highland), woinadega (midland) and kola (lowland) respectively (CDC, 2008). Average annual rainfall amount varies between 1000 to $1500 \mathrm{~mm}$ and average annual temperature is $23^{\circ} \mathrm{c}$ (SARDO, 2009).

Out of the estimated total land area of 228,172 ha; 46,664 ha (44 percent) is arable land, 21,445 ha (10 percent) is used for grazing, 554 ha (1percent) is covered with natural forest and shrubs, 4,806 hectare ( 2 percent) covered with water, 9,765 ha (4 percent) is allocated for residential and infrastructure development, and 42,813 ha (39 percent) is not suitable for any economical purpose (CDC, 2008).

Housing Census of Ethiopia was conducted in May 2007, by using this year population projection result show that Simada has a total population of 269,765 of which $133,356(49.43$ percent) are males and $136,409(50.56$ 
percent) are females. About 251,800 (93.3 percent) are rural settler and 17,965 (6.7 percent) are urban dweller (CSA, 2014-17).

\subsection{Sampling Technique and Sample Size}

Simada district was purposively selected, because of the presence of large number of wheat producer households and its extent of production in the area. Even though the study district comprises of 39 rural Keble, only 13 consist of all in the wheat production. For this study, multi- stage sampling techniques was used to attain an accurate cross-sectional data from sample households in study area. In the first stage, 3 Kebels as listed in table 1were selected by using simple random sampling method from 13 Kebele which having higher area and potential under wheat production based on access good information within district agricultural extension service officers.

From 12,998 smallholder households who produce wheat in production season and relatively who have homogeneity in terms of their farm activity and other socio- economic characteristic, 154 total sample households was determined through basic formula provided by Yamane( 1967) and then, allocate 154 total samples size for each sampled Kebele through probability proportionality size of each Kebele . In the second stage, 154 sampled $\mathrm{HH}$ were selected from sampled Kebele with simple random sampling method. To determine the appropriate sample size 92 percent confidence level and 8percent level of precision were used.

$$
\mathrm{n}=\frac{N}{1+N\left(e^{2}\right)} \text {. }
$$

Table 3. 1 Total sampled household and sample size selection from each Keble

\begin{tabular}{|lcc|}
\hline Keble & Total household head & Sampled household head \\
\hline 1. Engudadar & 1234 & 61 \\
2.Bazra & 981 & 48 \\
3.Algana Ashera & 914 & 45 \\
4. Total & 3129 & 154 \\
\hline
\end{tabular}

Source: Kebele Administration Office in 2018

\subsection{Source of Data and Method of Data Collection}

For this study both primary and secondary data source were used. Primary data were collected from sampled households based on 2017/18 wheat production season. Primary data was collected through personal interviews by using data collection instruments or questionnaires with structured interviews schedules and key informant discussion. The questionnaire was include, issues on the demographic and institutional factors, input types, resources endowment and input amount used and output obtained by sample households during wheat production season.

For primary data collection, three enumerators were selected from the study area. Enumerators who know about the study area, acceptance from local farmers, experience in data collection and speaking local language. The questionnaire was ready after making necessary corrections and pre-test before actual use in order to obtain more clear information. The secondary data which were relevant to the research topic was used as supplementary information to support the primary information provided by the sampled households for rational and unbiased conclusion on research result. These include both published and documents which were collected from Agriculture office, Non-Governmental Organizations (NGO), Research Centers and Central Statistical Agency (CSA).

\section{LITERATURE REVIEW}

\subsection{Theoretical Literature}

\subsubsection{Wheat production and consumption in Ethiopia}

Ethiopia is the second largest wheat produce in Sub-Saharan Africa country after South Africa. Wheat is one of the most important cereal crops in Ethiopia in terms of both consumption and production and also in terms of caloric intake it is the second most important cereal crop in the country after maize. It is providing an estimated 12percent to the daily per capita caloric intake for the country's more than 90 million population (FAO, 2015). Wheat is mainly grow by smallholder farmer in the highland parts of Ethiopia, which present between 6 and $16^{0}$ $\mathrm{N}$ and 35 and $42^{\circ} \mathrm{E}$, at altitude ranges from 1500 to 2800 meters above sea level and with minimum temperature $6^{0}{ }_{\mathrm{c}}$ to $11^{0} \mathrm{c}(\mathrm{MoARD}, 2012)$. Wheat production mostly grown in the central and southeastern highlands of Ethiopia in June up to September and harvested in October up to November.

The most wheat producing area in Ethiopia includes Arsi, Bale, and parts of Shoa are considered the more wheat growing area. In Ethiopia, wheat production covers an area of 1.6million hectares with a total production of 3.9 million tons yearly with average yield in 2013 production season was $2.4 \mathrm{t} / \mathrm{ha}$ which is below around 70 percent and 30 percent of Egypt's and world average respectively (FAO, 2013).

Wheat production in Ethiopia's for self-support is only 75 percent and the residual 25 percent of wheat has to be imported commercially and through food aid in other country (Abu, 2014). In Ethiopia, both bread and durum wheat produced in production season through 92 percent and 8 percent of small holder and large farmers 
respectively. Both crop species are highly important for agro-processing industries; bread wheat variety has gained much popularity over durum wheat. As GOE estimates that above 4.5 million farmers are annually participated on wheat production, however at rest does not satisfy the country's yearly domestic demand. Consequently, a large quantity of wheat is imported every year to balance the increasing domestic consumption demand.

The country is ongoing on a rapidly growing rate of urbanization and increased expansion newly starting food processing industries that have support for increased demand for durum wheat products such as macaroni and spaghetti in the urban market in Ethiopia. In 2008/9, the GOE started importing wheat through EGTE which greater than before the domestic supply of wheat at a subsidized price in order to reduce domestic market prices (AACCSA, 2016).

\subsubsection{Concepts of technical efficiency in production}

According to (Coelli et al.2005) technical efficiency is the level to which the maximum possible output is achieved from a given combination of available inputs. Any deviation from the maximal output is typically considered as technical inefficiency. Hence, the presence of shortfalls in efficiency means that output can be increased without requiring extra conventional inputs and call for new technologies (Binam et al., 2004). If this is the case, then empirical measures of efficiency are obligatory issue in order to determine the magnitude of the gain that can be obtain from improving performance in production with available resources.

Technical efficiency refers to the physical relation between factor of production and output without consider the monetary value of input and output. A technically efficient position is achieved when the maximum possible improvement in output is obtained from a set of resource. An intervention is technically inefficient if the same (or greater) outcome could be produced with less of one type of input (Palmer and David, 1999).

According to Farrell (1957) technical efficiency is the ability of a firm to produce a maximum output from a given level of inputs, and technology, or achieve a certain output threshold using a minimum quantity of inputs, under a given input and technology.In other words, a measure of technical efficiency indicates the extent to which a farm could produce additional output without changing the levels of inputs used if it were to operate on the production frontier, which is determined by the best-practice farms. Based on Farrell measure of technical efficiency can be obtained by using input and output quantity without introducing prices of these inputs and outputs. Then, one producer is more technically efficient if it produces an output level higher than another producer with the same level of input usage and technology. Technical efficiency means the ability to avoid waste by producing as much output as input usage allows or by using as little input as output production allows (Lovell, 1993). That means ability of farms to employed the better practice in the production process so, that not more than the necessary amount of a given set of inputs is used in producing the best level of output.

As many document described technical efficiency of an individual farmer as the ratio of observed output to its corresponding stochastic frontier output, given the levels of the inputs used by the farmer (output approach)or the ratio of the minimum possible amount of inputs to the observed required input to produce the given output (input approach). Therefore, the level of technical efficiency of a particular producer is characterized by the relationship between observed production and potential production. On other hand measurement of producer specific technical efficiency is based upon gap between observed outputs from efficient production frontier. If a producer actual production point lies on the production frontier, it is perfectly efficient and otherwise technically inefficient, with the ratio of the actual to the potential production defining the level of efficiency of the individual farmer.

\subsection{Technical Efficiency Measurement}

Measuring productivity and efficiency are very important when evaluating production units, the performance of different industries or that of a whole economy. It enables to identify sources of efficiency and productivity differentials, which is essential to policies designed to improve performance of producer.

After Farrell (1957), the modeling and an empirical estimation of efficiency has been given emphasis which played a vital role in stimulating many others towards such modeling. Since there have been many developments and refinements in the methodology of efficiency measurements. There are controversial issues as to the efficiency of different methodologies in measuring technical efficiency. The measure of technical efficiency is derived by seeing how the performance of individual producers within a farm compares with the farm frontier function.

The technical efficiency of an individual production unit is measured by its deviation from the frontier function. Since in actual practice this frontier function is difficult to known, it must be estimated from a sample of observed production units and each producer's performance is compared with the estimated frontier to indicate the technical efficiency of the individual firm (Tedla, 2002).

Technical efficiency measurements are basically carried out using frontier methodologies, which shift the average response functions to the maximum output or to the efficient firm. These frontier methodologies are broadly divided two frontier methodologies; these are; parametric and non parametric frontier models.

The parametric frontier model may further be classified into deterministic and stochastic frontier models. The parametric models are basically estimated based on econometric methods and the non parametric technical 
efficiency model, often referred to as data envelopment analysis (DEA), involves the use of linear programming method to construct a non parametric 'piecewise' surface over the data (Coelli et al., 1998). The choice of specific frontier model based on many considerations issue such as, the type of data, cross-sectional or panel data, the underlying behavioral assumptions of firms, the relevance to consider and extent of noise in the data and the objective of the study, but various issues pertaining to model specification are still debating( Fekadu,2004).

\subsubsection{Non parametric methods}

The non-parametric method, first developed by Farrell (1957) and more expand by Charnes, Cooper and Rhodes (1978) is called Data Envelopment Analysis (DEA). The non-parametric /mathematical programming approach is applied in agricultural productions as one measure of technical efficiency. The nonparametric methods use mathematical linear programming methods to measure relative efficiency of units commonly referred to as Decision Making Units (DMUs). The most common nonparametric methods are the DEA and the more general FDH.

A piecewise frontier is constructed based on data points that use the least inputs in producing a particular level of outputs. Relative efficiency is measured by comparing observed performance against best-practice performance. The nonparametric methods differ from the parametric in that the former does not make any a priori assumptions about the functional form of the production function and distribution of the inefficiency term. The basic DEA and FDH are deterministic, thus attributing all deviations from the frontier is due to inefficiency. This lead exaggerates the effect of inefficiency in the model. The most common method of estimating efficiency in DEA is a radial measure based on Farrell (1957) concept of radial contraction of inputs to the least level necessary for production of a specific level of output. In output space, the radial measure can be thought of as radial expansion of output obtainable from a given combination of inputs. The nonparametric techniques of DEA and FDH provide information on the shadow prices of inputs and outputs of the DMUs. DEA is able to handle multiple outputs and multiple inputs without requiring price data (Collier et al., 2011).

The deterministic nature of the basic DEA is usually cited as its main weakness as it fails to account for stochastic noise in data which could potentially bias the estimated efficiency scores The DEA is also argued to be less robust to outliers and extreme values and lacks parameters for economic interpretation (Daraio and Simar, 2007).

\subsubsection{Parametric method}

The characteristics parametric methods involve econometric modeling of the production process and it requires a priori assumptions on the functional form of the production function and distribution of the inefficiency term. The common functional forms of the production function based on literature are the Cobb-Douglas and the trans-log models. The distribution of the inefficiency term includes half normal, exponential, truncated normal and gamma distribution. The main criticism against using these distributions for decomposing the residual is that there is often not any priori theoretical justification for selecting any of these distributions. Furthermore, the issue of selecting between different distributions according to which one fits best the data is not trivial, as the likelihood function to be maximized in each case is often significantly different. Parametric frontier model can further be classified into deterministic and stochastic frontier methods.

Deterministic frontiers are regression based and attribute all deviations from potential production is due to inefficiency without considering random error in the model. Deterministic frontiers may be estimated using Corrected Ordinary Least Squares (COLS) or Modified Ordinary Least Squares (MOLS). Unbiased estimates of the slope parameters in both estimation procedures are obtained using OLS followed by a correction of the intercept. In COLS, using the largest positive observed residual while MOLS modifies the intercept using the mean of the assumed one-sided distributed disturbance term (Kumbhakar and Lovell, 2000).

According Coelli (1995) one of the criticisms of the deterministic approach is that no account is taken of the possible influences of measurement errors, bad weather condition and other noises up on the shape and positioning of the estimated frontier. However, stochastic frontiers model (SFM) takes into account both statically noise errors which arises from like measurement errors and errors which arise from inefficiency components.

Aigner et al. (1977) and Meeusen and Van den Broeck (1977) introduced simultaneously the idea of composed error to overcome the problems with the deterministic models in the cross-sectional context. The method is mostly employed in a simple case of stochastic production functions with a single-output and multiple-inputs. Stochastic frontier approach has found wide acceptance within the production economics literature, because of their consistency with theory and relative ease of estimation

The original specification involved a production function specified for cross-sectional data that had an error term with two components, one to account for random effects and another to account for technical inefficiency. The stochastic frontier model follows Battese and Coelli (1995) consists of two equations, one to represent the production frontier and a second to measure technical inefficiency. The stochastic frontier model can be formulated as follow:

$\mathrm{Yi}=\mathrm{f}\left(\mathrm{X}_{\mathrm{i}} ; \beta\right) \exp \left(\varepsilon_{\mathrm{i}}\right)$

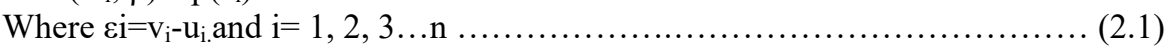


Here, $Y_{i}$ represents the observed output level of the $i^{\text {th }}$ small holder farmers; $X_{i}$ represent the actual input quantities used by small holder farmers for production; $\mathrm{f}($, )is the type frontier production function like CobbDouglas type or Translog for the $\mathrm{i}^{\text {th }}$ firm; $\beta$ stands for the vector of unknown parameters to be estimated in SFM and $n$ represents the number of sample smallholder farmers ; $\varepsilon_{\mathrm{i}}$ is the disturbance term of the model composed of two elements $\left(v_{i}\right.$ and $\left.u_{i}\right)$ Where $v_{i}$ is a random error that accounts for the stochastic effects beyond the farmer's control like; weather condition and bad luck, measurement errors as well as other statistical noises in the data and assumed to be independent to $u_{i}$.

Conversely $u_{i}$ refer the technical inefficiency of the producer and it is non-negative half-normal random variables with zero mean and constant variance $\delta^{2}$ i.e. Half-normally distributed to $\mathrm{N}^{+}\left(0, \delta^{2}{ }_{\mathrm{ui}}\right)$. The random error, $\mathrm{V}_{\mathrm{i}}$, which are assumed to be independently and identically distribution as $\mathrm{N}\left(0 \delta_{\mathrm{vi}}^{2}\right)$, it can be positive or negative and so the stochastic frontier outputs vary about the deterministic part of the frontier model (Coelli et al., 1998).

From Equation (1), the technical efficiency $\left(\mathrm{TE}_{\mathrm{i}}\right)$ for an individual producer/farmer is estimated as; $\mathrm{TE}_{\mathrm{i}}=$ Yi

$\overline{\mathrm{f}(\mathrm{Xi} ; \beta) \exp (\varepsilon \mathrm{i})}$

$\mathrm{TE}_{\mathrm{i}}=\frac{\mathrm{f}(\mathrm{Xi} ; \beta) \exp (\varepsilon \mathrm{i}=\mathrm{vi}-\mathrm{ui})}{\mathrm{f}(\mathrm{Xi} ; \beta) \exp (\mathrm{vi})}=\exp (-\mathrm{ui})$

This is called Timmer index. This concept will be used in this paper .Because there is wheat output shortfall in Ethiopia as well as in study area. This reference to output oriented measure of technical efficiency (Debreu, 1951; Farrell, 1957). The question is how to obtain maximum (frontier) or best practice output?. This can be obtaining by estimation parameter vectors using parametric and non parametric approach.

Where;

$\mathrm{TE}_{i}$ (the ratio of actual output to potential or frontier output) is technical efficiency of the $\mathrm{i}^{\text {th }}$ farmer; $\mathrm{Y}_{\mathrm{i}}$ represents the output for the $\mathrm{i}^{\text {th }}$ firm; $\mathrm{f}\left(\mathrm{X}_{\mathrm{i}} ; \beta\right) \exp \left(\mathrm{v}_{\mathrm{i}}\right)$ is the stochastic frontier output and $\mathrm{vi} \sim N\left(0 \delta_{\mathrm{vi}}^{2}\right)$ and $\mathrm{u}_{\mathrm{i} \sim} \mathrm{N}^{+}$ $\left(0, \delta^{2}{ }_{\text {ui }}\right)$.

The stochastic frontier can be estimated using maximum likelihood estimation (MLE) to obtain consistent estimates of the slope parameters. The conditional distribution of the estimates can be used to obtain conditional expected values of inefficiency for each observation. The main weakness of stochastic frontier analysis is its parametric nature. The need to specify the functional form of the production function a priori makes it susceptible to bias resulting from functional form misspecifications.

Another argument in different document relates to the comparison of individual units against an average practice frontier rather than best practice in the sample being analyzed in SFM. Also, SFM fails to allow for analysis of technical efficiency in multiple outputs without output price information (Collier et al., 2011). With multiple outputs, the output variable is usually measured as an aggregate monetary value rather than physical units. The use of SFM for multiple outputs is argued to be inappropriate as it may underestimate efficiency (Alene et al., 2006). But, if one is using farm level data where measurement error, missing variables and bad weather condition are likely to play a significant role on measurement of technical efficiency level.

Then, assumption that all deviations from the frontier are due to inefficiency, which is made by non parametric method of technical efficiency measurement, may be a heroic assumption.

Different empirical studies on technical efficiency analysis in agriculture activity used stochastic frontier model due to different variation nature of agricultural output like; it is affected by natural hazard, climatic condition and measurement errors that could attribute to the presence of noise in the data. So as to account for such random noise most recent studies on technical efficiencies in agriculture have used stochastic frontier model. For this reason the stochastic frontier method is recommended for use in this study than other model.

\subsection{Empirical Studies on Technical Efficiency and its Determinants}

Production efficiency analysis in agriculture and other sector has been studied by different researchers in abroad and Ethiopia. Most studies have been specified the Cobb-Douglas type Productions functions and commonly estimate parameters by using the MLE procedure. Some of these empirical studies on technical efficiency in agricultural production are given as follow.

\subsubsection{Empirical studies on technical efficiency and its determinants from abroad}

Waluse (2012) estimate determinants of common bean productivity and efficiency, a case of smallholder farmers in eastern Uganda by using 280 households selected with a multi-stage sampling techniques and Cobb-Douglas production function form, the result show that bean productivity was positively influenced by plot size, ordinary seeds, certified seeds and planting fertilizers and mean of technical efficiency among bean farms was 48.2percent. Two limit Tobit model estimation revealed that technical efficiency was positively influenced by value of assets at $1 \%$ level and extension service and group membership at 5 percent level; while age and distance to the factor market negatively influenced technical efficiency at 10percent and 5percent levels respectively.

Baloyi et al.(2012)determinants of technical efficiency among small-scale maize producers in Ga-Mothiba of the Limpopo province in South Africa. They used Primary data from 120 maize farm households obtained in a purposive sampling procedure and Cobb-Douglas production function was used to analyze the technical efficiency. 
There results of the estimation showed that there were significant positive relationships between farm size and fertilizer with technical efficiency. There results of the study also revealed that there was a significant negative relationship between cost of tractor hours and technical efficiency. The study further revealed that small-scale maize producers in Ga-Mothiba are experiencing decreasing returns to scale indicating that small-scale farmers are experiencing technical inefficiency in maize production.

Study by Magreta (2011) Economic efficiency of rice production in smallholder irrigation schemes a case of Nkhate irrigation scheme in southern Malawi. The Study used a parametric frontier approach and trans-log stochastic production function to analyze technical, allocative and economic efficiency of smallholder rice farmers. Results revealed an average technical, allocative and economic efficiency levels of 65pecent, 59 percent and 53 pecent respectively. This suggests that farmers have a rice yield potential of 35 percent to be exploited. The study shows that Soil fertility status, access to credit, household size and farmers experience were the factors that influence the efficiency levels of smallholder rice farmers in study area.

According to study made by Wan Roshidah et al.(2017) on determinants of technical efficiency among cocoa farmers in Malaysia during the year 2013 production season using parametric approach, the stochastic frontier production is based on the Cobb-Douglas production function and Tobit estimator for determinant of technical efficiency and 323 smallholder cocoa farmer in Malaysia data were collected. The results of the analysis showed that ratio, number of clones, record keeping, status of farmers (either part-time or full-time basis), knowledge, farming course and plant location affects efficiency.

\subsubsection{Empirical studies on technical efficiency and its determinants from Ethiopia}

Analysis of economic efficiency estimation and identification of their determinants in mixed crop and marketdriven vegetable production systems in two districts of eastern Ethiopia were undertaken by Jema (2008). The study used both DEA and SFA methods and the results based on the comparison of the two production systems showed a significant technical inefficiency in the study area. He revealed that variables such as farm size, education, extension visit, asset value, family size, farm distance, level of consumer spending and large family size are determinants of technical inefficiency.

Analyzing the technical efficiency of haricot bean seed production in Boricha district of Sidama zone, southern Ethiopia was undertaken by Abebayehu (2011). He used cross-sectional data collected from 120 haricot bean seed multiplying farmers during 2010/11 production season. Technical efficiency was estimated and analyzed using the Cobb-Douglas functional form. The estimated stochastic production frontier model indicates that input variables such as land under haricot bean, DAP fertilizer, seed and oxen are found to be important in increasing the average level of haricot bean output. The result of the study showed that there were technical efficiency differentials among haricot bean seed multipliers of the study area.

The estimated mean level of TE of haricot bean seed producers was 0.695 . This reveals that there exists a possibility to increase the level of haricot bean output by about $30 \%$ through exploiting the existing local practices and technical knowledge of the relatively efficient farmers. Among the farm specific socioeconomic and institutional factors hypothesized to affect the level of technical efficiency, off/non-farm income, intercropping practice, family size, and market distance had significant negative effect on the level of technical efficiency; whereas, education, livestock holding, and membership in seed multiplying cooperative affect technical efficiency positively and significantly.

Getahun (2014)Technical efficiency of smallholder farmers in onion production in Dugda woreda, East Shewa zone. He used Cobb-Douglas functional form and Cross sectional data from 110 irrigated and 50 nonirrigated onion producing farmers were collected during 2011/12 production season. The estimated stochastic production frontier model indicated that input variables such as area of onion plot, urea fertilizer, expenditure on seed, expenditure on pesticides and tractor power in case of irrigators were found to be important factors in increasing the level of onion output. The result further revealed that there were significant differences in technical efficiency among onion producers in the study area.

Study on technical efficiency of smallholder farmers growing malt barley in Debark Woreda using cross sectional data collected from 120 sample households in 2010 cropping season by Endalkachew (2012). CobbDouglas functional form with maximum likelihood estimation method was he used in a single estimation procedure to estimate the technical efficiency. The result shows mean efficiency of 0.805 and thus the existence of about 19 percent technical inefficiency in the production of malt barley. The implication of the result is that efficiency improvement efforts could lead to up to 19 percent productivity gain with the same level of resource and technology use. The results also revealed that malt barley area; horsepower in plowing, value of credit inputs and number of plowing are the determinants of the production level. The MLE result has also indicated determinants of inefficiency. The significant negative coefficients of age, education, malt barley experience, soil fertility, and livestock holding implied that efficiency improves with increase use of these inputs. On the other hand, family size, age square and plot distance appeared with positive coefficients, denoting the increment in these factors lead to diminishing technical efficiency. 


\section{Methods of Data Analysis}

To achieve the objectives of the study, descriptive and inferential statistics and also econometric analyses were used. Descriptive statistics was used to measure central tendency and measure of dispersion and to descript some important characteristics of the sampled households. Inferential statistics like likelihood ratio and chi-square $\left(x^{2}\right)$ test were used to inference population by using sample households. Under econometric analyses, stochastic frontier production and inefficiency model were employed to measure the level of technical efficiency and identify determinants of technical inefficiency with single stage estimation method.

\subsection{Selection of Production Function}

The limitation of SFM is to pre-determine a functional form and assume the distribution for technical inefficiency (half-normal, gamma, truncated and exponential) for the evaluation of technical inefficiency. Among the possible algebraic forms of production function, Cobb-Douglas and translog functions have been the most popularly used models in the most empirical studies of agricultural production analysis.

When decisions about the function must be made, it is recommended to estimate a number of alternative models and to select a preferred model using the likelihood ratio test (Coelli and Battese, 1996). As most efficiency studies with stochastic frontier used either a Cobb-Douglas (CD) or Translog (TL) type of production functions. In this study, both CD and TL production function were specified and the most appropriate model was selected based on log-likelihood ratio tests. Therefore, within given different factors of production, both the log-log linear (double log) form of Cobb-Douglas and Translog production function for this study is defined as follow.

The log linear form of CD production function mathematically can be formulated as

$\ln \mathrm{Y}_{\mathrm{i}=} \beta_{0+} \sum_{j=1}^{n} \beta_{j} x_{i j}+V_{i}-U_{i}$

The log linear form of Translog production function mathematically can be formulated as

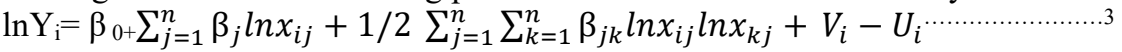

Where ln denotes the natural logarithm; $n$ represent total number of input variable which include in CobbDouglas or traslog production function for the purpose of wheat production; j represents the each number of inputs used by smallholder farmer in wheat production; $i$ represents the $i^{\text {th }}$ farm in the sample; $Y_{i}$ represent the actual output of the $i^{\text {th }}$ sample farmer; $X_{i j}$ denotes $j^{\text {th }}$ farm input variables used in wheat production of the $i^{\text {th }}$ farmer; $\beta$ stands for the vector of unknown parameters to be estimated; The symmetric component ( $\left.\mathrm{v}_{\mathrm{i}}\right)$ is assumed to be independently and identically distributed as $\mathrm{N}\left(0, \sigma^{2}{ }_{\mathrm{v}}\right)$. On the other hand, $\mathrm{u}_{\mathrm{i}}$ captures the technical inefficiency of the farmer and the distributional assumption of the technical inefficiency term, $\mathrm{u}_{\mathrm{i}}$, was estimate using the likelihood ratio test. Based on likelihood ratio test $C D$ production function was employed for this study, elasticity of scale for producers can be estimated as the sum of partial elasticity of output with respect to each input. The elasticity of scale or return to scale measures the responsiveness of output to a proportional increase in all inputs in the long run (Coelli et al., 2005).

$\mathrm{E}(\mathrm{x})=\sum_{j=1}^{n} \frac{\partial \ln y}{\partial \ln x j}=\sum_{j=1}^{n} \beta j$

Aigner et al. (1977) proposed the log likelihood function for the model in equation (1) assuming half normal distribution for the technical inefficiency effects $\left(\mathrm{u}_{\mathrm{i}}\right)$. They expressed the likelihood function using lammda $(\lambda)$ parameterization, where $\lambda$ is the ratio of the standard errors of the non-symmetric to symmetric error term (i.e. $\lambda=$ $\left.\sigma_{\mathrm{ui}} / \sigma_{\mathrm{vi}}\right)$. However, according Battese and Corra (1977) proposed that the $\gamma$ parameterization, where $\gamma=\sigma_{\mathrm{ui}}^{2} /$ $\left(\sigma^{2} v_{i}+\sigma^{2} u_{i}\right)$, to be used instead of $\lambda$. Because the value of $\lambda$ could be any non-negative value while $\gamma$ ranges from zero to one and better measures the distance between the frontier output and the observed level of output resulting from technical inefficiency. Consistent with Bravo and Pinheiro (1997) there is association between gamma $(\gamma)$ and lammda $(\lambda)$ which can be written as: $\gamma=\left[\frac{\lambda^{2}}{1+\lambda^{2}}\right]$

These lammda and gamma represent are variance parameters in the model that can be estimated by ML. The parameter $\gamma$ (gamma) measures the difference between frontier and observed levels of output and can be interpreted as the total variation in output from the frontier attributable to technical inefficiency. It has a value between zero and one. The value of zero implies that the non-negative random variable, $u_{i}$ (inefficiency) is not present from the model and the value of one show the absence of statistical noise from the model and hence low level of actual output compared to the maximum output of the other farm that is totally a result from inefficiency of smallholder farmers.

In this study, the likelihood ratio test were used to select the appropriate functional form that best fits the data, appropriate distributional assumption of the technical inefficiency term and the existence of inefficiency or not on the model and others. Then, number of hypothesis tests was run in this study using the likelihood ratio test which gives as in the following equation.

$\mathrm{LR}=\lambda=-2 \ln [L(\mathrm{H} 0) / L(\mathrm{H} 1)]$ 6

$\lambda=-2[\ln L(\mathrm{H} 0)-\ln L(\mathrm{H} 1)]$

Where, $\lambda$ is the likelihood ratio (LR), 
$L(\mathrm{H} 0)=$ the log likelihood value of value of the null-hypothesis;

$L(\mathrm{H} 1)=$ the $\log$ likelihood value of the alternative hypothesis; and $\ln$ is the natural logarithms. The value of likelihood ratio compare with the significance level of 1 percent, 5 percent and 10 percent with point for the $\chi^{2}$ distribution and the decision were made based up on the model result of LR and critical value of $\chi 2$ distribution within the given degree of freedom.

\subsection{Estimation of Technical Efficiency}

The stochastic frontier model was separately developed by Aigner et al. (1977) and Meeusen and van Den Broeck (1977). This model is appropriate to estimate technical efficiency level in agricultural production, because agricultural production in general exhibits shocks, and hence there is a need to separate the influence of stochastic variables (random shocks and measurement errors) from resulting estimates of technical inefficiency (Battese ,1992). On other hand, the error term in the stochastic frontier model is assumed to have two components namely: a symmetric component which represents the effect of statistical noise and other error component hold systematic influences that are unexplained by the production function and which are attributed to the effect of technical inefficiency (Tijani ,2006).

Due to Aigner et al. (1977) and Meeusen and van Den Broeck (1977), the stochastic frontier model is defined as:

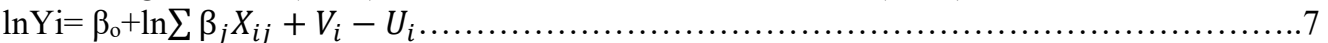

Here $\ln$ denotes the natural logarithm; $j$ represents the number of inputs used; $i$ represent the $i^{\text {th }}$ farm in the sample; $Y_{i}$ represents the observed wheat production of the $i^{\text {th }}$ farmer; $\mathrm{X}_{\mathrm{ij}}$ denotes $j$ th farm input variables employed in wheat production of the $\mathrm{i}^{\text {th }}$ farmer; $\beta$ stands for the vector of unknown parameters to be estimated. The random error $\left(\mathrm{v}_{\mathrm{i}}\right)$ accounts for the external factors beyond the small holder farmer's control, like weather, diseases, measurements errors and fluctuation in prices of inputs as well as other statistical noises and ui is non-negative random variable which shows the technical inefficiency in wheat production relative to other uncontrolled factor. The technical efficiency in stochastic frontier model can be defined as the ratio between the actual outputs to the corresponding maximum output due to Timmer measurement of technical efficiency.

$\mathrm{TE}_{\mathrm{i}}=Y_{i} / Y^{*}$ .8

Where $Y_{i}=f\left(X_{i}, \beta\right) \exp \left(v_{i}-u_{i}\right)$ and $Y^{*}=f\left(X_{i}, \beta\right) \exp \left(v_{i}\right)$

Therefore equation $(8)$ can be written as

$\mathrm{TE}=\frac{\mathrm{f}(\mathrm{Xi}, \beta) \exp (\mathrm{vi}-\mu \mathrm{i})}{\mathrm{f}(\mathrm{Xi}, \beta) \exp (\mathrm{vi})}=\exp \left(-\mathrm{u}_{\mathrm{i}}\right)$

The range of the technical efficiency is between 0 and 1 . If $u_{i}=0$ it means that the sample farmers are fully efficient in wheat production and lie on the frontier. This indicates that there is no inefficiency and the error term is only the factors that are outside from the farmer control. If $\mathrm{u}_{\mathrm{i}}>0$ it means the sample farmers lie below the frontier which indicates that the farmers face the problem of inefficiency in wheat production and make losses due to inefficiency.

\subsection{Estimation Steps and Distribution Assumption of Technical Inefficiency}

The SFM consists of two sets of equations. The first equation specifies the stochastic production frontier that relates wheat output to farm inputs employed in wheat production. The second equation specifies the inefficiency models that represent technical inefficiency with vector of socioeconomic characteristics of the wheat producers. Therefore, there are two main steps that help to examine determinants of technical efficiency from stochastic production function. These, include one-step and two-step estimation method.

In one-step estimation method the stochastic frontier production function model and technical inefficient models are estimated in one step maximum likelihood estimation approach by independent and simultaneous without additional programming. In two- step estimation method the first estimate the stochastic frontier production function and specific technical efficiency level for agricultural production by considering various functional forms and second estimate the determinants of technical efficiency by regress various socio-economic variables against the technical efficiency values obtained from estimates of maximum likelihood.

However, according to (Chirwa, 2007) two-step has been criticized because farmers' knowledge of its level of inefficiency may affect choice of inputs. This step has major shortcoming emanate from inconsistency that could be created from the assumptions related in the distribution of inefficiency in the estimation of technical inefficiency model and stochastic production model. Based on different literature review, there are four assumptions for the distributions of technical inefficiency indicator $\left(u_{i}\right)$, namely, half normal, truncated normal, exponential and gamma. But the technical efficiency scores in this study were predicting by half normal distribution due to its simplicity in computation of the coefficients of parameters in stochastic frontier model.

\subsection{Variables in Technical Efficiency Measurement Production function variable}

OUTPUT (Y): This is dependent variable under stochastic frontier production function model. It is the amount of 
wheat will attain from the given factor of production in cropping season by the sample farmer thorough rain-fed farming and measure in kilogram.

INPUT: Defined as the factor of production used in the production of wheat namely: land, labor, oxen, DAP, urea and seed used for wheat production.

LAND: It is the total area of plot(s) in hectare used for production of wheat.

LABOR: It is the total amount of man day used for different agronomic practices (plowing, planting, weeding, cultivation and harvesting) of wheat production during production season

SEED: It refers to the total quantity of wheat seed in kilogram by each sample farmer.

UREA: Total amount of urea fertilizer used by each sample farmer for wheat production and measured in kilogram

DAP: It reference the total amount of Di-Ammonia Phosphate (DAP) fertilizer employed for the production of wheat by each sample farmer and measured in kilogram.

OXEN- POWER: It is the amount of oxen-power employed for plowing wheat land preparation to planting and measured in oxen-days by the each sample farmer

Determinants of technical inefficiency in wheat production

The dependent variable was the technical efficiency scores each farmer, which was computed from stochastic frontier model with Cobb -Douglas production function.

Independent variables: these denoted different factors hypothesized to explain differences in technical efficiency among farmers in wheat production. These were

Credit: this is a dummy variable that represents access to credit for farm related purposes by the smallholder sample farmer. If the farmer has taken credit during the given production season, the variable takes a value of 1 , and 0 otherwise.

Education: this variable is measured as continuous variable in year of schooling and use as a proxy variable for managerial ability.

Number of plowing: this is measure as discrete variable and characterize by the frequency of plowing performs on wheat plot of each sample farmer

Extension contact: this variable is measure as a discrete variable of the frequency of contacts with extension workers in a year.

Family size: this variable is measure as discrete variable by taking the total number of family members in the household.

Land ownership : it is considered as a dummy variable, which can taking a value of 1 smallholder farmer have property right on wheat production land and 0 if the land is his/her owned or rented.

Seasonal migration (Smigration): it is consider as a dummy variable that takes a value of 1, if household head become season migrant from their residence area to other area during off time of wheat production season and 0 , otherwise.

Sowing system: it is considered as a dummy variable that takes a value of 1 , if household head use raw sowing on wheat production season and 0 , otherwise

Farm record keeping: it is consider as a dummy variable that takes a value of 1 , if household head have farm record keeping on wheat production season and 0 , otherwise.

Livestock holding: this variable stands as continuous variable for the number of livestock owned by the household in tropical livestock unit (TLU).

According to Coelli and Battese (1996) to examine the determinant of technical inefficiency score, the following technical inefficiency model was employed. Because, technical inefficiency model was used to identify factors that influence technical efficiency level among farmers in wheat production within study area and the model could be estimated as follow;

$\mathrm{U}_{\mathrm{i}}=\delta_{0}+\delta_{1} Z_{1}+\delta_{2} Z_{2}+\quad \delta_{3} Z_{3}+\quad \delta_{4} Z_{4^{+}} \quad \delta_{5} Z_{5}+\delta_{6} Z_{6} \quad \delta_{7} Z_{7}+\delta_{8} Z_{8}{ }^{+} \delta_{9} Z_{9}+$

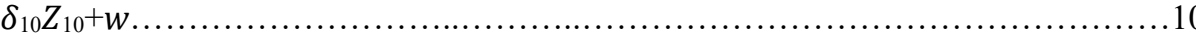

Where;

$\mathrm{U}_{\mathrm{i}}$ refers to the technical inefficiency score of small holder farmer in wheat production. $\delta_{0}, \delta_{1} \ldots \delta_{10}$ are parameters to be estimate by ML in single stage estimation is unobserved random error term and $Z_{1} \ldots . . Z_{10}$ refers to factors which are include characteristic of smallholder farmer.

\section{RESULTS AND DISCUSSIONS}

\subsection{Descriptive statics result of demographic characteristics of sample households}

Aged Household head $(\mathrm{HH})$ has the source of good farming experience and able to participate risk involving farm activity than younger farmers. The average age of the sample households during the survey period, was about 47 years with standard deviation of 10 (table 2) which was less than 65.97 year of average life expectancy for both sex in Ethiopia (WPP,2017). Based on Strock et al., 1991 (as cited in Ermiyas ,2013) this average value of age included in the most economically active age group of 17-50 year. Education is a tool to improve the quality of labor by improving the knowledge and managerial skill gap of farmer for all agricultural activity and have a 
tendency to adopt new technologies. The average education level of literate sample household heads during survey period was about 3 years with the minimum of zero years (illiterate) and maximum of 15 years (table 2). From the total respondent 54 percent were illiterate and the other 46 percent respondent were literate (table 3 ).

Family size plays an important role in wheat production and most farmers depend mainly on family labor. The average family size of the sample households was 6 persons per household (table 2) which is greater than 4.6 person per household as Ethiopia, based on household size and composition around the world in 2017. Table 2 .Age, education level and family size of $\mathrm{HH}$

\begin{tabular}{llllll}
\hline Variable description & Observation & Minimum & Maximum & Mean & Std. Deviation \\
& & & & & \\
\hline Age of household head & 154 & 22 & 75 & 47.05 & 10.06 \\
Education level of HH & 154 & 0 & 15 & 2.96 & 2.89 \\
Family size of HH & 154 & 3 & 11 & 6.37 & 1.676
\end{tabular}

Source: Own computation (2018)

\section{Land holding characteristics of sample households}

Land

As current econometric evidence shows land is one of conventional factors of production for agricultural output which limit agricultural production and food security, which is needed by all $\mathrm{HH}$ to achieve their livelihood phenomena. The average own land holding of the sample HH in study area was about 1.67 ha, from these amount of land, about 1.44ha used for cultivation and the remain used for grazing and homestead purpose ( table 4).

Table 3.4 Farming characteristics and land distribution for wheat by sample household

\begin{tabular}{lcccc}
\hline Variable & Minimum & Maximum & Mean & Std. Deviation \\
\hline Total own farm land & 0.5 & 3 & 1.67 & 0.59 \\
Total cultivated land & 0.5 & 2.75 & 1.44 & 0.52 \\
Total land for wheat & 0.25 & 1.75 & 0.86 & 0.36 \\
Frequency of plowing & 2 & 4 & 2.97 & 0.59 \\
Frequency of contact with DA & 1 & 13 & 6.77 & 1.99 \\
Distance to market in km & 3 & 41 & 19.99 & 10.12
\end{tabular}

Source: Own computation (2018)

The number of plowing for land preparation helps appropriate germination of the seed and which have it on contribution for wheat yield. The average frequency of plowing land for wheat production was 3. Farmers were being visited more frequently while others have no chance at all to be visited by extension workers. Accordingly, sample households were being visited by extension workers on average 7 times with the minimum of 1 time and maximum of 13 times during 2017/18 wheat production year (table 4). The average distance from the village town which have farm cooperative, credit provider institution, farm training, health, market access for transactions and secondary school center was 20 kilometer (table 4).

\section{Production function of inputs and output variables}

The production function for this study was including six inputs which were used by wheat producer sampled household. As table 8 presented on average the sample household produced 23.58 qt of wheat, which is the dependent variable for the production function. As result show the productivity level was low compare to the country average productivity 26.75 qt but higher than 20.67 qt as south Gondar zone. The land allocated by sampled household during survey period for wheat production ranges from 0.25 up to 1.75 ha with an average of 0.87 ha of land. 
Table4. 4 Input output variable used in production function

\begin{tabular}{cccccc} 
Variable & Observation & Mean & Std. Deviation & Minimum & Maximum \\
\hline Output (quintal) & 154 & 23.58 & 12.64 & 4 & 48 \\
Labor (man-day) & 154 & 37.35 & 15.16 & 10 & 95 \\
Oxen (oxen-day) & 154 & 10.68 & 3.73 & 3 & 19 \\
Seed (kg) & 154 & 158.50 & 55.23 & 50 & 250 \\
DAP (kg) & 154 & 119.74 & 49.87 & 20 & 225 \\
Urea (kg) & 154 & 67.54 & 34.04 & 10 & 200 \\
Land (ha) & 154 & 0.86 & 0.36 & 0.25 & 1.75 \\
\hline
\end{tabular}

Source: Own computation (2018)

On average, the amount of seed that the sample household used for wheat production was 158.50 kilogram. The other important input which contribute for wheat production was DAP and urea. On average sampled household was used 120.38 and 68 kilogram DAP and urea respectively. Like other input labor and oxen was inputs which was support wheat production in study area. On average 10.68 and 37.35 oxen day and man day was used for wheat production respectively in study area.

\section{Institutional and other characteristics of sample households Extension and credit access}

Access to extension service is one of the institutional instruments to promote sustainable agricultural productivity in Ethiopia. Accordingly, sample households were being visited by extension workers on average 7 times with the minimum of 1 time and maximum of 13 times during 2017/18 wheat production year (table 4). Access to credit may enable farmers to purchase productive inputs on time and it may lead to higher productive efficiencies for farmers. Out of the total sampled household only 11percent sampled household used credit from Abkute in study area. The remain 89 percent of sampled household not used formal source of credit rather than used informal credit source like their relatives (table 9).

Internal seasonal migration was thought to be a natural process in which surplus labor was gradually withdrawn from the rural area to provide needed manpower for urban and other rural area which has of temporal shortage of labor availability. As table 9 show that only 30 percent of respondent participates on internal seasonal migration in order to obtain additional income sours during off time of wheat production.

Landownership, according to the information obtained from the woreda agricultural offices; currently land redistribution had not taken place in the woreda. As a result, landownership is obtained through inheritance up on death of families, rent in and through sharing of crops. As table 9 show that from the total sampled farmer 82 percent of farmer were used their own land for wheat production and the remain 18 percent of sampled farmer may used land for wheat production form rent in and through sharing of crops.

Row sowing, raw planting used for proper allocation of resource like fertilize and easily control the amount of weed in wheat production. Row planting with reduced seeding rate, and proper implementation of agronomic best practices increased wheat yield. As the above table show that only 25 percent of sampled household participated on raw sowing cropping pattern, but 75 percent of sampled household applied broadcast sowing pattern in study area. Traditionally, more sampled farmers in Simada woreda sowing wheat seeds using hand broadcasting. But, broadcasting sowing method reduces wheat yields due to lacking proper contact wheat seed to soil fertility and delayed germination, higher competition between plants for inputs (fertilizer), because of uneven wheat seed distribution, and difficulty in controlling grassy weeds.

Record keeping, used to provide proof of income and expenses to the internal revenue and to use as a decisionmaking tool for each agricultural production activity. Farmer may need to maintain two sets of farm records production levels and financial transactions. Production records keep includes agricultural inputs and outputs: crop yields, livestock born and lost. Financial records such as operating expenses, equipment, feed and seed purchases, wages and interest and loan payments. As table 9 show that from the total sampled household $23 \%$ of sampled household attempt to used record keeping even if there is lack of proper and documented record. 
Table 4.5 Institutional and other characteristics of sample household

\begin{tabular}{llccc} 
Variable & $\begin{array}{c}\text { Yes } \\
\text { frequency }\end{array}$ & Percent & No & Prequency \\
& & & & Percent \\
\hline Land ownership & 127 & 82.47 & 27 & 17.53 \\
Credit access & 17 & 11.04 & 137 & 88.96 \\
Record keeping & 35 & 22.73 & 119 & 77.27 \\
Row sowing & 39 & 25.32 & 115 & 74.68 \\
Seasonal migration & 46 & 29.87 & 108 & 70.13
\end{tabular}

Source: Own computation (2018)

\section{Econometric Results}

Before proceeding to the next discussion related to estimation and interpretation of results of SFM model parameters, from which individual level of technical efficiency may be estimated, the multicollinearity problem for continues and discrete explanatory variable by Variance Inflation Factor (VIF) and contingency coefficient(CC) respectively was checked. Moreover, Breusch-Pagan test was used to detect the presence of hetroskedasticity in data or not. If VIF value greater than 10 is usually show the strong multicollinearity, whereas a value loss than 10 suggests that no strong multicollinearity problem between continues explanatory variable. As rule of thumb show if contingency coefficient is greater than 0.75 the variable have multicollinearity, if it is less than 0.75 no multicollinearity problem (Gujarati, 2004). Moreover, Breusch-Pagan test would be used to detect the presence of hetroskedasticity in data or not and also variation tests were carried out. As appendix 1, 2 and 3 showed that there was no strong multicollinearity and hetroskedasticity problem on research data (Appendix 1).

\section{Hypothesis testing}

One attractive feature of stochastic frontier model is that, it is possible to test various hypotheses using maximum likelihood ratio (LR) test, which were not possible in non-parametric models. Therefore, before discussing about parameter estimates of production frontier function and the inefficiency effects, it is advisable to run the several hypotheses tests for further analysis and interpretation. Accordingly, to do this two hypothesis test were conducted for this study, one to choose an appropriate production function, two to check whether the explanatory variables in the inefficiency effect model contribute significantly to the technical efficiency variations among wheat producing households in study area. Using maximum likelihood estimation and wish to test whether certain parameter restrictions are supported by the data, one useful and very convenient test is likelihood ratio test. Based on table 11, the first hypothesis was concerned about the selection of appropriate functional form that adequately fit the given data. In order to select frontier model that fits the data well, two functional forms Cob-Douglas and Translog production function specifications were considered. Accordingly, the null hypothesis of the study CobDouglas production function is the appropriate functional form that adequately fits the data set $\left(\mathrm{H} 0: \beta 7 \ldots \mathrm{B}_{21}=\right.$ 0 ) and also the alternative hypothesis of the study translog production function is appropriate function form that adequately fits the data set $\left(\mathrm{H} 1: \beta 7 \ldots \mathrm{B}_{21}\right.$ are different from zero). For this study, likelihood ratio test was used to select the best specification, among the two production function, that describes the data well. The likelihood ratio test here is calculated based on the formula stated under the equation (8) in chapter three. This value was compared with tabulated chi-square. As shown table 11 the null hypothesis was rejected in half- normal distributional assumptions at 1percent level of significance. This indicates that the result from the Cobb-Douglas was more accurate and consistent compared to translog production function.

Table 4. 6 Test of hypothesis

\begin{tabular}{lccll}
\hline Null hypothesis & Test statistic $(\mathrm{LR})$ & D.F & Critical value & Decision \\
& & & & \\
\hline 1. H0: C-D $(\beta 7 \ldots \beta 21=0)$ & & & & \\
Half normal & 34.76 & 21 & 38.93 & Fail to reject H0 \\
4. H0, $\delta_{1} \ldots \delta_{14}=0$ & 31.24 & 10 & 23.20 & Reject H0
\end{tabular}

\section{Source: Own computation (2018)}

After selecting Cobb-Douglas production function in stochastic frontier model best fits the data with halfnormal distribution assumption of inefficiency, the second hypothesis was that all explanatory variables in technical inefficiency effect model are simultaneously equal to zero, H0: $\delta_{1} \ldots \delta_{10}=0$. To test this hypothesis log- likelihood ratio was calculated using the value of the log likelihood function under the Cobb-Douglas production function in stochastic frontier model (a model without explanatory variables of inefficiency effect model, H0) and the full frontier model (a model with all explanatory variables of inefficiency effect model, H1). 
As table 11 show the calculated value of LR equals to 31.24 while the critical likelihood ratio $(\chi 2)$ of upper 1 percent level of significance at 10 degree of freedom equals to 23.20.Since, the likelihood ratio (LR), value was greater than the critical value of LR, $\left(\chi^{2}\right)$, at 10 degree of freedom with upper 1percent level of significance, the null hypothesis that determinant variables in the inefficiency effect model are simultaneously equal to zero was rejected at 1 percent level of significance. Therefore, the explanatory variables associated with inefficiency effect model are jointly different from zero.

\section{Parameter estimates of the SFM}

Allowing for the estimates of frontier production function where the farmers' production technology is represented by the Cobb-Douglas production function, estimation was made using a single-stage estimation procedure for both parameters of stochastic frontier model and inefficiency model. The stochastic frontier model was used the equation 4 and 12 to estimate the model by using the STATA version 14 computer programs. The model include of 16 parameters; among these 6 of which were associated with the explanatory variables (factor of production for wheat) of the frontier production function, 10 were associated with the explanatory variables influencing the level technical efficiency and other parameters associated with the distribution of random error $\left(v_{i}\right)$ and $\left(u_{i}\right)$.

Table 4.7 Maximum estimates for SFM with CD production function

\begin{tabular}{llllll}
\hline \multicolumn{1}{c}{ Variable } & parameter & Coefficient & Std. Deviation & $\mathrm{z}$ & $\mathrm{p}>|\mathrm{z}|$ \\
\hline Constant & $\beta_{0}$ & -0.99 & 0.615 & -1.62 & 0.105 \\
lnland & $\beta_{1}$ & $0.36^{* * *}$ & 0.105 & 3.52 & 0.000 \\
lnseed & $\beta_{2}$ & $0.45^{* * *}$ & 0.129 & 3.55 & 0.000 \\
lnoxen & $\beta_{3}$ & 0.11 & 0.101 & 1.14 & 0.254 \\
lnDAP & $\beta_{4}$ & 0.07 & 0.091 & 0.86 & 0.389 \\
lnurea & $\beta_{5}$ & $-0.14^{*}$ & 0.080 & -1.78 & 0.076 \\
lnlabour & $\beta_{6}$ & $0.55^{* * *}$ & 0.079 & 7.00 & 0.000 \\
Return to scale & 1.22 & & &
\end{tabular}

\begin{tabular}{lccc}
\hline Variance parameter & & \\
Sigma_v & 0.28 & Lambda & 0.64 \\
Sigma_u & 0.18 & Gamma & 0.29 \\
Sigma2 & 0.11 & &
\end{tabular}

Note $* * * *$, significant at $10 \%$ and $1 \%$ level of significance

Source: Own computation (2018)

The above table results reveal that estimated coefficients of the stochastic frontier model have expected signs except urea. As table 12 shows that land, labor and seed were positive and significant at l percent level of significant and also urea was negative and significant at 10 percent level of significant. This is may be due to lack of properly utilization of urea by farmers. As result indicted, increasing the availability of land, labor and seed can be increase production of wheat significantly as study expected. However, oxen and DAP were positive insignificant variables for wheat production in study area. This is may be due to utilization problem of these insignificant inputs by farmers. One of the important features of the Cobb-Douglas production functional is the direct interpretation of its parametric coefficients (input coefficients) as a partial elasticity of production or partial productivity of input with given output produced.

This situation permits one to evaluate the potential effects of changes in the amount of each input on wheat output. The parametric coefficients of input or partial elasticity of significant input variables were 0.36 for land, 0.55 for labor, 0.45 for seed and -0.14 for urea. These values for each factor of production shows that the relative contribution of each input in wheat production.

Decisions in economics are always made based on the margin. As result 1 percent increasing the utilization of these input for wheat production were provided increase the amount of wheat output until certain point with 0.36 percent, 0.55 percent and 0.45 percent of land, labor, and seed by assume other factor of production were constant. But, 1 percent increasing the utilization of urea for wheat production was provided decreasing the amount of wheat output with 0.14 percent by assume other factor of production were constant. The magnitude of each coefficient of the significant input indicates that farm output was inelastic to change in any of these input used..

The highest coefficient of labor (0.55) indicated that labor was the main determinant input of wheat production in the study area .As result wheat production was relatively more sensitive to labor utilization than other inputs. When aggregate the coefficients of parameters for significant input by using the equation 6 , which provide total factor productivity (scale elasticity or returns to scale). This value was 1.22 scale coefficients in this case; this study indicated that farmer's under wheat production in the study area holds increasing return to scale. 
As result show it was inconsistent the assumption of constant return to scale (homogeneous) for C-D production function. This is may be due to non response and response error, and (e.g. weather, topography, distribution of supplies input, measurement error, etc) and non-negative random variables assumed to account for technical inefficiency in production. This implies that there was potential for wheat producer to continue to expand their production, because they were in the stage I of production surface, where resource used and production was believed to be inefficient. The implication of such a result is that proportional and simultaneous increase of all production inputs can provide a more than one proportional increase in output of wheat. This result was consistent with (Endalkachew, 2012; Solomon, 2012).

\section{Estimation of farmer level technical efficiency in wheat production}

One of the main objectives of this study is to measure the technical efficiency levels of smallholder wheat producer in Simada district in 2017/18 production season. From the allowed CD production function and the distributional assumptions made about the two error terms $v_{i}$ and $u_{i}$, the technical efficiencies were estimate. The estimation result shows that the mean technical efficiency level of wheat producers was 79 percent $\left(\mathrm{TE}_{\mathrm{i}}<1\right)$ provides a measure of the shortfall of observed output from maximum feasible output and their efficiency ranges from the most inefficient level of 35 percent which was far below from efficient frontier by 65 percent to the highest level of efficiency was 98percent which was only 2 percent away from the frontier (100 percent) with 0.13 standard error (table 13). This variation in the technical efficiency of wheat producers was probably due to differences in managerial decisions and farm characteristics that may affect the ability of the producer to adequately use the existing technology.

As result show farmers participated in wheat production during 2017/18 in the study was not efficient and on average 21 percent of the wheat output was lost due to inefficiency of producers. This indicates that on average farmers can increase their current level of output by 21 percent without increasing additional inputs, or, the result show those smallholder farmers on the average can decrease their current levels of inputs consumption by 21 percent without reducing currently level of output.

Table 4.8 Technical efficiency score with frequency for sample household

\begin{tabular}{lccc}
\hline TE score (\%) & Frequency & TE score (\%) & Frequency \\
& & & \\
\hline $35-45$ & 3 & $68-78$ & 33 \\
$46-56$ & 5 & $79-89$ & 59 \\
$57-67$ & 20 & $90-100$ & 34 \\
Mean & & 0.79 & \\
Maximum & & 0.98 & \\
Minimum & & 0.35 & \\
Std. Deviation & & 0.13 & \\
& & &
\end{tabular}

Source: Own computation (2018)

From the total sampled farmer 39.62 percent of respondent were produced below the mean level of technical efficiency, 38.31 percent of respondent produced on around the mean of technical efficiency and the remain22.08percent were produced above the mean of technical efficiency.

This could be show with graphically as follow 


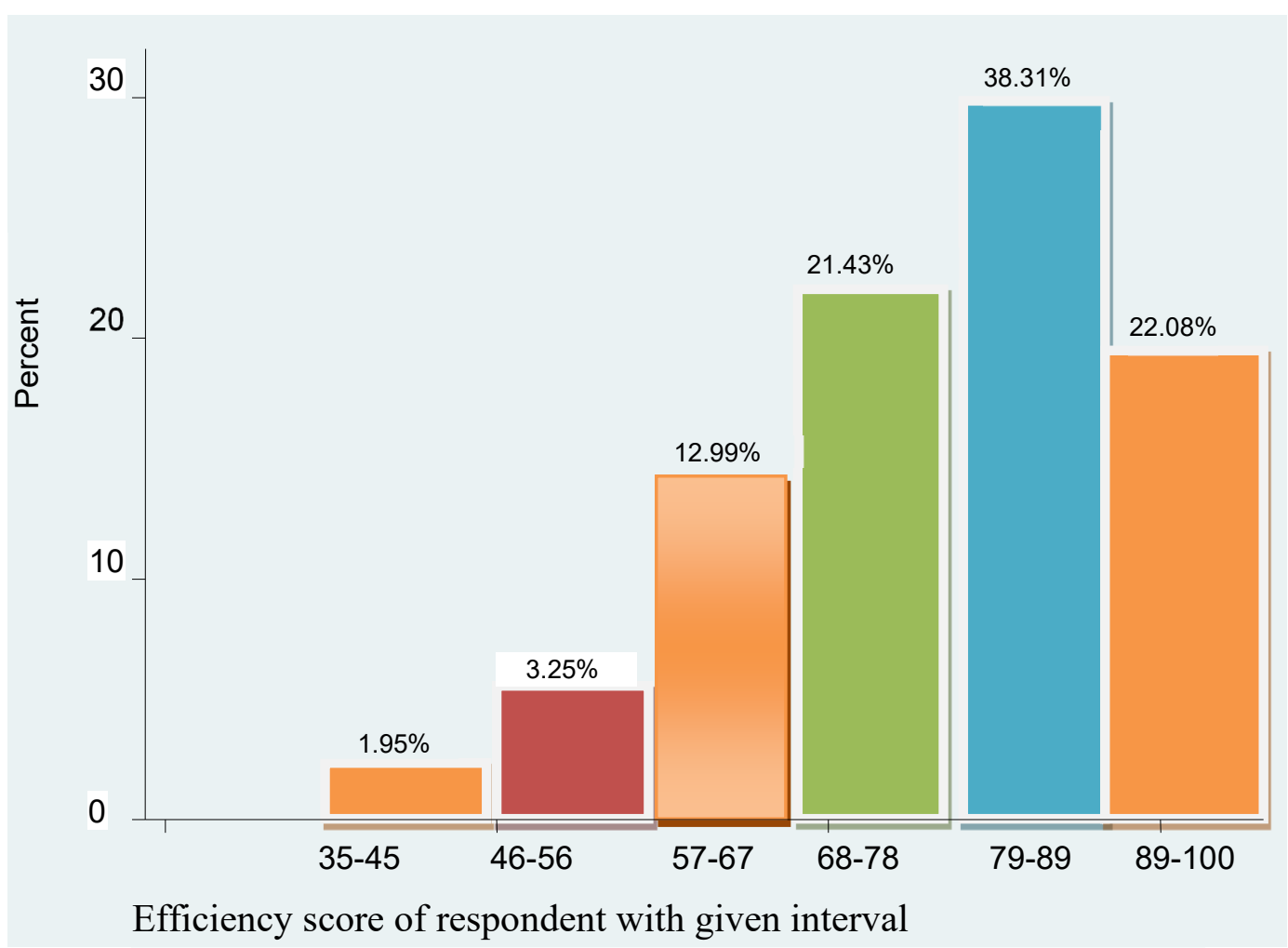

Figure 4.5 Show percentage distribution of individual TE level

\section{Potential output and yield gap due to technical inefficiency}

The technical efficiency in stochastic frontier model can be defined as the ratio between the actual outputs to the corresponding maximum output due to Timmer measurement of technical efficiency in chapter three equation10and11. After obtaining TE score of individual sampled farmer, as Kibara (2005) stated potential output would be estimated through the following formula. Potential output $=\frac{\text { Actual output }}{\text { Technical efficeincy }}$

Yield gap due to technical inefficiency may be defined as the difference between technically full efficient yield (Potential output) and observed yield (actual outputs). Therefore, yield gap is the amount which represents give up yields due to technical inefficiency. Based on equation above and using the values of the actual wheat output obtained and the predicted technical efficiency score, the potential wheat output was estimated for each household in wheat production within a given ha. The mean result was presented in table below.

Table4. 9 Potential output and yield gap due to technical inefficiency

\begin{tabular}{lll}
\hline Variable & Sampled household head & Mean \\
\hline Actual output (qt) & 154 & 23.58 \\
Mean of TE & 154 & 0.79 \\
Potential output (qt) & 154 & 29.84 \\
Yield gap (qt) & & 6.26 \\
\hline
\end{tabular}

Source: Own computation (2018)

As observed in above table mean technical inefficiency was 21 percent, it arias from 29percent inefficient used of resource, which leads 6.26qt yield gap of wheat on the average value of the actual output and the potential output of $23.58 \mathrm{qt}$ and29.84qt respectively. Therefore to reach the production possibility frontier of the wheat production from this low level, enhancing efficient utilization and allocation of resources is crucial issue in Ethiopia as well as in study area.

\section{Determinants of technical inefficiency}

The estimated level of technical efficiency among smallholder farmers is not enough to derive recommendations for policy intervention. It is also necessary to identify the sources of variation in the technical efficiency estimates among the farmers and quantify their effect. Based on the above result, having the information about the existence of technical inefficiency in input used and other farm practices .Since, measuring its magnitude, identify the major factors causing this inefficiency level is the next most important objective of the study.

As different Empirical studies on efficiency showed that the determinants of inefficiency very considerably 
and highly dependent on demographic and other characteristics of farmer (educations status, family size, frequency plowing, sowing system, seasonal migration, record keeping existence), resource endowment factor (livestock and land ownership), institutional factor(access to credit and frequency of extension contact) Therefore, those above variables considered as determinants of inefficiency in this study by assuming other determinant is constant. The coefficients of those socio-economic and institutional variables included in the inefficiency model are estimate simultaneously by the single-stage ML estimation procedure using the estimated level of TE as dependent variable. According to Coelli (1995) in the analysis of technical inefficiency effects model, the sign of coefficients of the model is taken in to account based on the analysis study.

If the coefficient of the parameter in the model is positive, it means that the variable is increasing the level of technical inefficiency of the farmer and whereas, if the sign of the coefficient of the parameter is negative, it shows that the variable under consideration is decreasing the level of technical inefficiency or increasing the level of technical efficiency of farmers.

Hence, the coefficients should be read as the effect of each variable (determinant) on the level of inefficiency. However, one can read the estimated coefficients determinant directly as the effect of the variable on technical efficiency by taking the opposite sign of respective coefficients for variable. Thus, the opposite signs of the coefficients of the variable in the model result may be required which readers should keep in mind while reading this section. From the variables entered in to the inefficiency model, the coefficients of the independent variables such as raw sowing system, education level and frequency of plowing were appeared with unexpected sign.

Table 4.10 Maximum likelihood estimate for inefficiency model with single estimation

\begin{tabular}{lccccc}
\hline Variable & Parameter & Coefficient & Std. Deviation & $\mathrm{Z}$ & $\mathrm{p}>|\mathrm{z}|$ \\
\hline Constant & $\delta_{0}$ & -4.973 & 1.689 & -2.94 & 0.003 \\
Smigration & $\delta_{1}$ & 0.333 & 0.384 & 0.87 & 0.385 \\
Row sowing & $\delta_{2}$ & $1.554^{* *}$ & 0.739 & 2.10 & 0.036 \\
Recode keeping & $\delta_{3}$ & -0.122 & 0.399 & -0.31 & 0.760 \\
Credit access & $\delta_{4}$ & $-0.0005^{*}$ & 0.0002 & -1.86 & 0.062 \\
Fplowing & $\delta_{5}$ & $1.314^{* * *}$ & 0.400 & 3.28 & 0.001 \\
Education level & $\delta_{6}$ & $0.129^{*}$ & 0.071 & 1.80 & 0.071 \\
TLU & $\delta_{7}$ & -0.108 & 0.078 & -1.38 & 0.168 \\
Fextention of contact & $\delta_{8}$ & $-0.037^{*}$ & 0.020 & -1.78 & 0.075 \\
Landownership & $\delta_{9}$ & -0.660 & 0.569 & -1.16 & 0.247 \\
Family size & $\delta_{10}$ & -0.129 & 0.121 & -1.07 & 0.286 \\
\hline
\end{tabular}

Note $*, * *, * * *$, significant at $10 \%, 5 \%$ and $1 \%$ level of significance, respectively

Source: Own computation (2018)

However, the coefficients of other independent variables have expected sign of the study. As above table 15 showed that the variables that were statistically significant in affecting TE differentials include; education level, raw sowing, credit access, frequency plowing and frequency of extension contact. But, the coefficients of variables like landownership, seasonal migration, family size, TLU and record keeping were found to be statistically insignificant (there is no evidence for the significances of variable).According to table 15 factors which significantly affect technical efficiency wheat production in study area were described below.

Credit access: Credit availability can solve the problem of the cash constraint and enabling the farmers to purchase agricultural inputs timely that they cannot easily obtain by their own resources. As result of above table showed that credit have a positive influence on technical efficiency of wheat production and it was significant at 10 percent of significant level. Farmers with access to credit are better able to access expensive efficiency enhancing technologies like modern inputs and agricultural tools than other who were not access credit. This is in line with the findings of (Getahun, 2014; Ermiyas, 2013; Musa, 2013).

Education level: is expected to enhance managerial and technical skills of wheat producer farmers in study area. However, the coefficient of the variable entered into the technical inefficiency effect model show that the variable was significant at 10 percent level of significant and negatively affects level of technical efficiency in wheat production. This may be due to the fact that farmers who were more educated could join non farm sector provided that most farmers want to leave farming sector if they do have job opportunity. This probably will reduce labor availability towards wheat production including supervision and productivity enhancing activities. The finding is consistent with the findings of (Musaba and Bwacha, 2014; Alemayehu, 2010).

Raw sowing: raw planting used for proper allocation of resource like fertilize and easily control the amount of weed in wheat production. But, the finding of the study revealed that there was negative and significant relationship between raw sowing and technical efficiency of wheat production at 5 percent level of significant. This is may be due to the availability of labor and delay raw sowing time of wheat production in study area.

Frequency of plowing (Fplowing): increase in the frequency of plowing in hand will increase the level technical efficiency of wheat production by assuming that other variables are held constant. However, the finding of the study shows that there was negative and significant relationship between frequency of plowing and technical 
efficiency of wheat production at 1 percent level of significant. This may be due to continuously and over plowing of the land leads the problem of soil erosion and finally leads the gap between actual outputs from maximum output.

Frequency of extension contact (Fextention of contact): the coefficient of extension contact in this study was positive as expected and significant at 10 percent of significant level, suggesting that such frequency of extension contact increases farmer technical efficiency, because farmers are able to use modern techniques of wheat production activity, involving land preparation, planting, application organic and inorganic fertilizer and properly harvesting of wheat output. The chance that farmers who have frequently extension contact is more important for modern agricultural input mobilization, input use and disease control and which enables them to reduce technical inefficiency.

Thus increasing the frequency of development agent visit farmers who produce wheat is very importance to provide effective agricultural extension services in study area. The contribution of increasing numbers of frequency of farmers contact with extension agents can reduce the gap between the efficient and inefficient wheat producer farmers from the study area. As such situation stimulates farmer's adoption of agricultural technologies which is enable farmers improve their efficiency level in wheat production. This study is line with the previous findings of (Musa, 2013; Birachi et al., 2013).

\section{Marginal effect of inefficiency variable}

The estimated parameter on the inefficiency model presented in table 15 only indicate the direction of the effect the variable have on inefficiency level(were the negative parameter estimated shows that the variable increasing technical efficiency farmers in wheat production). Quantification of the marginal effects of these variables inefficiency model is important in order to estimate the change that will occur with respect to a change in one unit of that variable. Quantification of the marginal effects of inefficiency variables on technical efficiency level was done by partial differentiation of the technical efficiency predictor with respect to each variable in the inefficiency model Battese and Coelli, 1993 (as cited in Wambui ,2005).

\section{Table4. 11 Marginal effect of inefficiency variable}

\begin{tabular}{lcclcc}
\hline Variable & parameter & ME & Variable & parameter & ME \\
\hline Fplowing & $\delta_{1}$ & -0.089 & TLU & $\delta_{6}$ & 0.011 \\
Smigration & $\delta_{2}$ & -0.012 & Family size & $\delta_{7}$ & 0.006 \\
Row sowing & $\delta_{3}$ & -0.080 & Fextention of contact & $\delta_{8}$ & 0.002 \\
Recode keeping & $\delta_{4}$ & 0.0034 & Education level & $\delta_{9}$ & -0.010 \\
Credit access & $\delta_{5}$ & 0.00002 & Landownership & $\delta_{10}$ & 0.061 \\
\hline
\end{tabular}

Source: Own computation (2018)

The marginal effect of frequency of extension contact for technical efficiency indicated that, sample households considered increasing this variable by one percent, on average technical efficiency of sampled farmer in wheat production would increase by 0.2 percen In contrast marginal effect of Education level 0.01 show that, for sample households an increase in level of year of schooling by one year on average would decrease the level of technical efficiency by 1 percent than less educated.

The marginal effect of frequency of plowing 0.089 indicated that, for sample households increase in frequency of plowing by one percent would decrease the level of technical efficiency by 8.9 percent. The sampled farmer who access to used credit, the probability of farmer to be technical efficient would increase on average by 0.002 percent higher than those farmers who did not receive access to credit. The sample farmers who apply raw sowing system, the probability of farmer being technical efficient would decrease on average by 8 percent higher than those farmers who did not apply it. These above all marginal effect interpretations consider ceteris paribus.

\section{Summary and Conclusion}

The study aimed to analyze technical efficiency of Smallholder wheat producer farmer in Simada district of south Gondar zone in Ethiopia. The objective of study was to estimates technical efficiency level of each sampled household and to determine factors raise variations in technical efficiency among farmers in study area by using 2017/18 cross sectional data collected from wheat producer farmers from the district. Multi- stag sampling technique and personal interview through a structural interview scheduled was employed. For data analysis descriptive and inferential statistics and also stochastic frontier model with STATA version 14 were employed.

Ethiopia has high potential for wheat production and consumption. However, production of wheat does not sufficiently meet the demand of it, because of low productivity, even though a lot of research and development efforts made on high yielding varieties and other inputs. The productivity of wheat in Ethiopia and study area is still far below frontier yields. The productivity of wheat is not only determined by technological innovations alone but also by efficiency with which available technologies are used. Farmers use different levels of production inputs and management depending on their socio economic, institutional and environmental conditions.

The study observed that efficiency of wheat producer varied due to the presence of inefficiency effects which 
obtained from lack of frequently contact with extension worker, access to credit and lack of properly used education for wheat production and also due to, the problem of appropriate plowing frequency of land and applying raw sowing system. The study thus, indicated that on average farmers can increase their current level of output by 21 percent without increasing additional inputs. The estimated stochastic frontier model indicated land, labor and seed were significantly and positively influence wheat production at 1 percent of significant level and also urea was significantly and negatively influences wheat production at 10 percent of significant level. The production function of wheat by sampled farmer was holds increasing return to scale (1.22). As estimation result shows that the mean technical efficiency level of wheat producers was 0.79 and their efficiency ranges from the highest level 0.98 to 0.35 . The estimated gamma $(\gamma)$ parameter was about 0.29 .Among the farmer specific socioeconomic and institutional factors hypothesized that influence technical efficiency of farmers in wheat production, credit access and frequency of extension contact were significantly and positive influence the level of technical efficiency in wheat production at 10 percent of significance level. Education level was significantly and negatively influences the level of technical efficiency in wheat production at 10 percent of significance level. Raw sowing and frequency of plowing were significantly and negatively influence the level of technical efficiency in wheat production at 5 and 1 percent of significance level respectively.

\section{Recommendation}

According to the results of this study, some recommendations were suggested to be addressed either by the government or by any other concerned body. These are

The positive effect of credit access on TE needs financial strengthening together with awareness creation towards to enhance wheat production in particular and crop production in general. This study recommended that availability of credit facility which may capacitate the farmer to avoid financial shortage and untimely sailing livestock and other agricultural output in the case of different financial obligations. Therefore; any concerned bodies and different institutions should give emphasis towards organization of rural financial institutions and consistently follow up farmers for what purpose they used the availability of credit.

As study result show TE and education level has negative relation in wheat production, an effort by regional government towards increasing formal and informal schooling in study area is not sufficient condition for efficient utilization of agricultural input. Therefore, the government should give emphasis towards how the farmer can use their own basic education on each agricultural activity. Policies and strategies that provide improved extension services could help raise the efficiency of wheat production should be consistent and develop more than the current situation. Hence, the number of visit on the households by extension agents should be increase through provides training related to frequency of plowing of land and raw sowing system. Further, given the multiple of extension services, expansion of basic and functional educational provisions in the rural area must be considered as a key strategy for achieving increased smallholder households technical efficiency in study area.

\section{REFERENCE}

[1] Abebayehu, G. (2011).Technical efficiency analysis of haricot bean seed production, the case of Boricha district, Sidama Zone, Southern Ethiopia, In partial fulfillment of the requirements for the Degree of Master of Science in Economics. Haramaya University

[2] Abu, T. (2014). Ethiopian Grain \& Feed Annual Report, Approved by Quintin Gray on Grain Report no. ET1401, Addis Ababa.

[3] AACCSA (Addis Ababa Chamber of Commerce \&Sectoral Associations). (2016).Value Chain Study on Wheat Industry in Ethiopia. Afro Universal Consult \& General Trading Addis Ababa.

[4] Aigner, DJ., CA, Lovell \& PS, Schmidt. (1977).Formulation and Estimation of Stochastic Models, Journal of Econometrics, vol. 6, no.1, pp. 21-37.

[5] Alemayehu, E .(2010).Analysis of factors affecting the technical efficiency of coffee producers in jimma zone, a stochastic frontier analysis, the Degree of Master Science in Economics, Addis Abeba university.

[6] Alemayehu, S., Sinafikeh, A .\& Dorosh,p.(2011).Crop Production in Ethiopia Regional Patterns and Trends, Ethiopia Strategy Support Program II (ESSP II) Working Paper, No.0016

[7] Alene, A., V,Manyong.\& J,Gockowski.( 2006).The production efficiency of intercropping annual and perennial crops in southern Ethiopia, A comparison of distance functions and production frontiers Agricultural Systems 91: pp 51-70

[8] Baloyi, R .,Belete, A, Hlongwane,J., \& Masuku, M .(2012). Technical efficiency in maize production by smallscale farmers in Ga-Mothiba of Limpopo province, South Africa, African Journal of Agricultural Research, Vol. 7 no.40, pp. 5478-5482

[9] Battese, G .\& G, Corra.( 1977).Estimation of Production Frontier Model, With Application to the Pastoral Zone of Eastern Australia, Australian Journal of Agricultural Economics, Vol .21, no.1, pp.169-179.

[10] Battese, G.(1992).Frontier Production Functions and Technical Efficiency, A Survey of Empirical Applications in Agricultural Economics, Journal of Agricultural Economics, Vol .7 no.1,pp. 185- 208 
[11] Battese, G.E. \& T.J. Coelli, 1995. A Model for Technical Inefficiency Effects in a Stochastic Frontier Production Function for Panel Data. Empirical Economics, 20: 325-332

[12] Birachi K,W., Sibiko, G., Owuor,O. \& JK, Mwangi .(2013). Analysis of Determinants of Productivity and Technical Efficiency among Smallholder Common Bean Farmers in Eastern Uganda, Egerton University, Current Research Journal of Economic Theory, Vol.5, no.3,pp .44-55

[13] Bravo-Ureta,B.E .\& AE, Pinheiro.(1997). Technical, Economic and Allocative efficiency in Peasant Farming, Evidence from the Dominican Republic, Developing Economies, V0l.35.no.1,pp. 48-67.

[14] CDC (Center for Development Consultancy). (2008). A report on inventory and survey at sixty- four weredas in Amhara region. Addis Ababa.

[15] CIA(Central Intelligence Agency). (2016). A report with world fact book GDP composition by sector in Ethiopia.

[16] Charnes, A., W. Cooper .\& E. Rhodes.(1978). Measuring the Inefficiency of Decision Making Unit. European Journal of Operational Research, Vol 2: pp.429-44.

[17] Chirwa, E. W. (2007). Sources of technical efficiency among smallholder maize farmers in Southern Malawi. AERC research paper 172.African Economic Research Consortium, Nairobi, Kenya.

[18] Coelli, T.J.(1995).Recent Developments in Frontier Modeling and Efficiency Measurement. Australian Journal of Agricultural Economics, Vol 39: pp 219-245

[19] Coelli, T.J. \& Battese, G. (1996).Identification of factors which influence the technical inefficiency of Indian farmers. Australian Journal of Agricultural Economics, Vol, 40.no,2.pp,103-128.

[20] Coelli, T. J.,S. P. Rao.\& Battese,G.( 1998).An introduction to efficiency and productivity analysis. Kluwer Academic Publishers, Boston, Dordrecht/London, pp. 134-249

[21] Coelli, T.J., D.S. PrasadaRao, C.,O’Donnell \& G. Battese.( 2005).An Introduction to Efficiency \& Productivity Analysis. $2^{\text {nd }}$ Edn., Springer, New York, ISBN-10: 0387242651, pp: 349.

[22] Collier, T., A. Johnson. \& J, Ruggiero.(2011). Technical efficiency estimation with multiple inputs and multiple outputs using regression analysis. European Journal of Operations Research, 208: 153-160.

[23] CSA (Central Statistical Agency). (2014). Population Projection of Ethiopia for All Regions At Wereda Level from 2014 - 2017, Addis Ababa.

[24] CSA (Central Statistical Agency). (2016).Statistical Report on Area and Crop Production.Addis Ababa, Ethiopia.

[25] Daraio,C. \& Simar,L.(2007).Advanced Robust and Nonparametric Methods in Efficiency. Analysis Methodology and Applications. Springer science and business media, New York

[26] Endalkachew,Y.(2012).Technical efficiency analysis of malt barley production: the case of smallholder farmers in Debark woreda, north Gondar zone of the Amhara national regional state,Ethiopia .M.Sc. Thesis Presented to School of Graduate Studies of Haramaya University.

[27] Ermiyas, M. (2013.)Economic efficiency of sesame production in Selamago district of south Omo zone, southern Ethiopia, M.Sc. Thesis Presented to School of Graduate Studies of Haramaya University.

[28] Farrell, M. J.(1957).The measurement of productive efficiency. Journal of the Royal Statistical Society, Vol. 120, pp.253-290.

[29] Fekadu, G.(2004). Analysis of Technical Efficiency of Wheat Production: A Study in Machkel Woreda. M.Sc. Thesis Presented to School of Graduate Studies of Haramaya University. Ethiopia.

[30] FAO(Food \& Agriculture Organization) .(2015).Addressing marketing and processing constraints that inhibit Agri-food exports: A guide for policy analysts and planners. Agricultural Service Bulletin 160. Rome. Italy.

[31] FAO (Food \& Agricultural Organization). (2013). FAOSTAT DATABASE

[32] FHE (Food for the Hungry Ethiopia).(2017).Targeted Response for Agriculture, Income and Nutrition (TRAIN) Project. Second Quarter Report - January 01 to March 31

[33] Getahun.(2014).Technical efficiency in onion production: the case of smallholder farmers in Dugda woreda, east Shewa zone, Ethiopia. M.Sc. thesis presented to School of Graduate Studies of Haramaya University.

[34] Hasan, M. F. (2006). Economic Efficiency and Constraints of Maize Production in the Northern Region of Bangladesh. Journal of innovative development strategy Vol,1.no.1, pp,18-32.

[35] Housed size \& composition around the world. (2017).United nation, department of economics and social affair, population division, data booklet.

[35]Jema,H.(2008).Production efficiency of smallholders' vegetative dominated mixed Farming systems in Eastern Ethiopia: A non parametric approach. Journal of Africa Economies, 16: 1-27.

[36] James, W,Tim, S. \& Leulsegged, K.(2015).Woreda-Level Crop Production Rankings in Ethiopia: A Pooled Data Approach, .International Food Policy Research Institute (IFPRI) Addis Ababa, Ethiopia.

[37] Kaleb ,K .\& Workneh, N.(2016).Analysis of levels and determinants of technical efficiency of wheat producing farmers Ethiopian Institute of Agricultural Research, Addis Ababa University, Ethiopia. Vol. 11,no.36, pp. 3391-3403.

[38] Kibara, J .(2005). Techinical efficeincy of Kenya's maize production: An application of stochastic frontier 
approach. Msc thesis. Colorado State University

[39] Kifle,D. 2014). Economic efficiency of smallholder farmers in maize production in Bakotibe district, Oromia national regional state, M.Sc. Thesis Presented to School of Graduate Studies of Haramaya University. Ethiopia.

[40] Kinde, T.(2005). Technical efficiency of maize production: A case of smallholder farmers in Asosa Wereda. An M.Sc. thesis presented to School of Graduate Studies of Haramaya University. Ethiopia.

[41] Kumbhakar S.C.\& C.A.K. Lovell.(2000).Stochastic Frontier Analysis. Camber University Press, Cambridge, United Kingdom.

[42] Lovell,C.A.K.(1993).Production Frontiers and Production Efficiency. The Measurement of Productive Efficiency. New York: Oxford University Press.

[43] Meeusen, W. \&J. Van den Broeck. ( 1977).Efficiency Estimation from Cobb-Douglas Production Functions with Composed Error. International Economic Review, 18:435-444.

[44] Magreta, R .(2011). Economic efficiency of rice production in smallholder irrigation schemes: a case of Nkhate irrigation scheme in southern Malawi Master of Scienc (agricultural and applied economics) thesis in University of Malawi, Bunda College.

[45] Musaba,E and Bwacha,I .(2014).Technical Efficiency of Small Scale Maize Production in Masaiti District, Zambia. Journal of Economics and Sustainable Development Vol.5, No.4

[46] Musa ,H. (2013).Economic efficiency of smallholder farmers in maize production: the case of Arsi Negelle district, Oromia national regional state, Ethiopia, Msc Thesis in Agricultural Economics and Agribusiness, School of Graduate Studies of Haramaya University

[47] Palmer,M.\&David,H .(1999).Economics notes, National Primary Care Research and Development Centre, Centre for Health Economics, Centre for Health Economics, University of York, YO1 5DD.Publishing Group, BMJ VOLUME 31824 .

[48] SARDO (Simada Agriculture \& Rural Development Office. (2009). Call for development of Simada Wereda. Annual report, Wogeda

[49] Solomon, B. (2012). Economic Efficiency of Wheat Seed Production: The Case of Smallholders in Womberma Woreda of West Gojjam Zone. Msc, in Agricultural Economics ,Haramaya University, Ethiopia.

[50] MoARD (Ministry of Agriculture \& Rural Development).(2012).Ethiopia's Agricultural Sector Policy and Investment Framework (PIF) Ten year Road map (2010-2020),Draft Final Report MSPA (Mauritius Sugar Producers' Association), 2010.

[51] Tedla, B. (2002). Evaluation of Technical Efficiency of the Ethiopian Grain Mill Products Manufacturing Industry. Msc. Thesis Presented to the School of Graduate Studies of Haramaya University.

[52] Tijani, A. (2006). Analysis of the technical efficiency of rice farms in Ijesha land of Osunstate, Nigeria. Journal of Agriculture Economics, 45(2).

[53 ] Waluse, S. (2012).Determinants of common bean productivity and efficiency: a case of smallholder farmers in eastern Uganda. MSc thesis in agricultural and applied Economics of Egerton University

[54] WambuiK, (2005).Technical efficiency in Kenyan's maize production an application of the stochastic frontier approach. Msc thesis present in Colorado State University.

[55] Wan Roshidah F., Mukhriz I Azman A., Ahmad Z \& Abdul J .2017. Determinants of Technical Efficiency of Cocoa Farmers in Malaysia. International Journal of Supply Chain Management, Vol. 6, No. 1

[56] WAP (World Agricultural Production). 2017. Foreign Agricultural Service ,December 2017 Office of Global Analysis, Approved by the World Agricultural Outlook Board.

[57] WPP (World Population Projection). (2017). United Nations population estimates and projections.

[58 ] Yamane, T. (1967). Statistics: An Introductory Analysis $2^{\text {nd }}$ Edition. New York, Harper

\section{APPENDIX}

APPENDIX1: 1 Breush-Pagan test of hetroskedasticity

1. $\mathrm{H}_{\mathrm{o}}$, there is homoskedasticity

2. H1, there is no homoskedasticity

Steps in Breusch-Pagan test of hetroskedasticity

1. reg variables in frontier model

2. predict $\mathrm{u}$, residual

3. gen $\mathrm{u} 2=\mathrm{u}^{\wedge} 2$

4. $\mathrm{regu}^{\wedge} 2$ with variables in frontier model

5. got $L M$ by $=n R_{u i} \wedge 2$, where $n$ is number of observation and $R_{u i} \wedge 2$ is $R$-squared for residual

6. Compare the value got on number 5 with the $\mathbf{x}^{2}$ tabulated value with the given degree of freedom and significant level (1percent).

Decision; If calculated value greater than tabulated value reject Ho and visceral

1. $\mathrm{LM}=\mathrm{nR}_{\mathrm{ui}} \wedge 2=154 * 0.0690=10.626$ 
2. Chi-square $\left(\mathrm{x}^{2}\right)$ value in the table with given degree of freedom (6) and level of significant (1percent) $=16.81$. Which show that calculated value (12.5) less than tabulated value (16.81) therefore, failing to reject $H_{0}$.

APPENDIX: 1 Continuous variable include in stochastic frontier and inefficiency model

\begin{tabular}{r|rr} 
Variable & VIF & $1 / \mathrm{VIF}$ \\
\hline Inseed & 5.03 & 0.198913 \\
Inland & 4.52 & 0.221264 \\
Indap & 4.12 & 0.242436 \\
lnoxen & 3.76 & 0.265938 \\
lnurea & 3.39 & 0.294705 \\
lnlabour & 2.04 & 0.491177 \\
\hline Mean VIF & 3.81 & \\
vif & & \\
Variable & VIF & $1 / \mathrm{VIF}$ \\
\hline familysiz & 1.10 & 0.905254 \\
TLU & 1.09 & 0.921646 \\
freqextnco t & 1.05 & 0.953198 \\
educationl 1 & 1.03 & 0.969489 \\
fplowing & 1.03 & 0.974081 \\
\hline Mean VIF & 1.06 & \\
Source: & &
\end{tabular}

Source: Own computation (2018)

APPENDIX: 2Discrete variable include in inefficiency model

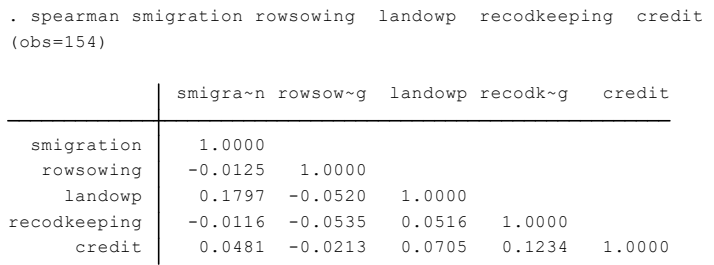

Source: Own computation (2018)

APPENDIX: 4 Stochastic Frontier Model with C-D production function

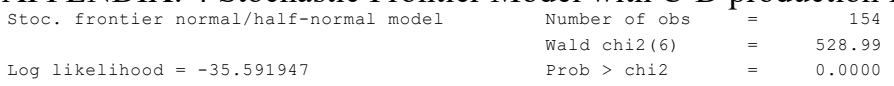

\begin{tabular}{r|rrrrrr}
\hline Inoutput & Coef. & Std. Err. & $z$ & P $>|z|$ & [92\% Conf. Interval] \\
\hline Inlabour & .6779729 & .0896864 & 7.56 & 0.000 & .5209602 & .8349857 \\
Inseed & .3518365 & .1295612 & 2.72 & 0.007 & .1250155 & .5786575 \\
Indap & .0470184 & .1011314 & 0.46 & 0.642 & -.1300309 & .2240676 \\
Inurea & -.0581086 & .0802595 & -0.72 & 0.469 & -.1986177 & .0824006 \\
Inoxen & .057967 & .1170976 & 0.50 & 0.621 & -.1470341 & .2629681 \\
Inland & .4936337 & .1089599 & 4.53 & 0.000 & .302879 & .6843884 \\
_cons & -1.031569 & .6541174 & -1.58 & 0.115 & -2.176723 & .1135853 \\
\hline /nnig2v & -2.515813 & .4014707 & -6.27 & 0.000 & -3.218662 & -1.812964 \\
/nnsig2u & -3.39461 & 2.589481 & -1.31 & 0.190 & -7.927979 & 1.138758 \\
\hline sigma_v & .2842485 & .0570587 & & & .2000214 & .4039429 \\
sigma_u & .1831765 & .237166 & & & .0189872 & 1.767169 \\
sigma2 & .1143508 & .0572185 & & & .0141793 & .2145224 \\
lambda & .6444237 & .2916902 & & & .1337657 & 1.155082 \\
\hline
\end{tabular}


APPENDIX: 5 Stochastic Frontier model with one stage MLE method

$\begin{array}{llll}\text { Stoc. frontier normal/half-normal model } & \text { Number of obs } & = & 154 \\ & \text { Wald chi2 }(6) & = & 488.12 \\ \text { Log likelihood }=-19.97098 & \text { Prob }>\text { chi2 } & = & 0.0000\end{array}$

\begin{tabular}{|c|c|c|c|c|c|c|}
\hline Inoutput & Coef. & Std. Err. & z & $\mathrm{P}>|\mathrm{z}|$ & [92\% Conf. & Interval] \\
\hline \multicolumn{7}{|l|}{ Inoutput } \\
\hline lnlabour & .5558326 & .0794389 & 7.00 & 0.000 & .41676 & .6949051 \\
\hline Inseed & .4595272 & .1293604 & 3.55 & 0.000 & .2330577 & .6859967 \\
\hline Indap & .0789184 & .0916348 & 0.86 & 0.389 & -.0815053 & .2393422 \\
\hline Inurea & -.1422094 & .0800124 & -1.78 & 0.076 & -.282286 & -.0021327 \\
\hline Inoxen & .1163325 & .1019174 & 1.14 & 0.254 & -.0620929 & .2947578 \\
\hline lnland & .369459 & .1050736 & 3.52 & 0.000 & .1855081 & .5534098 \\
\hline _cons & -.9986368 & .615993 & -1.62 & 0.105 & -2.077047 & .0797735 \\
\hline \multicolumn{7}{|l|}{$\operatorname{lnsig} 2 \mathrm{v}$} \\
\hline _cons & -3.12996 & .2419158 & -12.94 & 0.000 & -3.553478 & -2.706441 \\
\hline \multicolumn{7}{|l|}{$\operatorname{lnsig} 2 u$} \\
\hline smigration & .3339353 & .3841026 & 0.87 & 0.385 & -.3385078 & 1.006378 \\
\hline rowsowing & 1.55421 & .7392467 & 2.10 & 0.036 & .2600212 & 2.848399 \\
\hline familysiz & -.1292559 & .1210251 & -1.07 & 0.286 & -.3411329 & .0826211 \\
\hline fplowing & 1.314972 & .400871 & 3.28 & 0.001 & .6131725 & 2.016771 \\
\hline educationlevel & .1295054 & .0718379 & 1.80 & 0.071 & .0037398 & .255271 \\
\hline credit & -.000542 & .0002908 & -1.86 & 0.062 & -.001051 & -.0000329 \\
\hline landowp & -.6602965 & .5698177 & -1.16 & 0.247 & -1.657868 & .3372755 \\
\hline TLU & -.1081325 & .0784624 & -1.38 & 0.168 & -.2454956 & .0292306 \\
\hline recodkeeping & -.1222548 & .3994081 & -0.31 & 0.760 & -.821493 & .5769834 \\
\hline freqextncontact & -.0371319 & .0208509 & -1.78 & 0.075 & -.0736353 & -.0006286 \\
\hline _cons & -4.973909 & 1.689999 & -2.94 & 0.003 & -7.932567 & -2.015251 \\
\hline sigma_v & .2090922 & .0252914 & & & .169189 & .2584067 \\
\hline
\end{tabular}

APPENDIX: 6 Marginal Effect for determinant of inefficiency

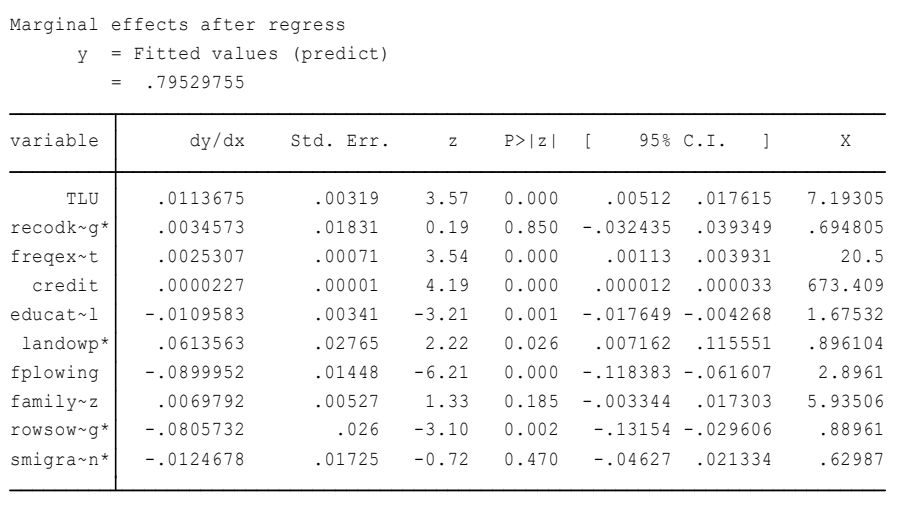

(*) $d y / d x$ is for discrete change of dummy variable from 0 to 1 
APPENDIX: 7 Normal Probability plot for random error

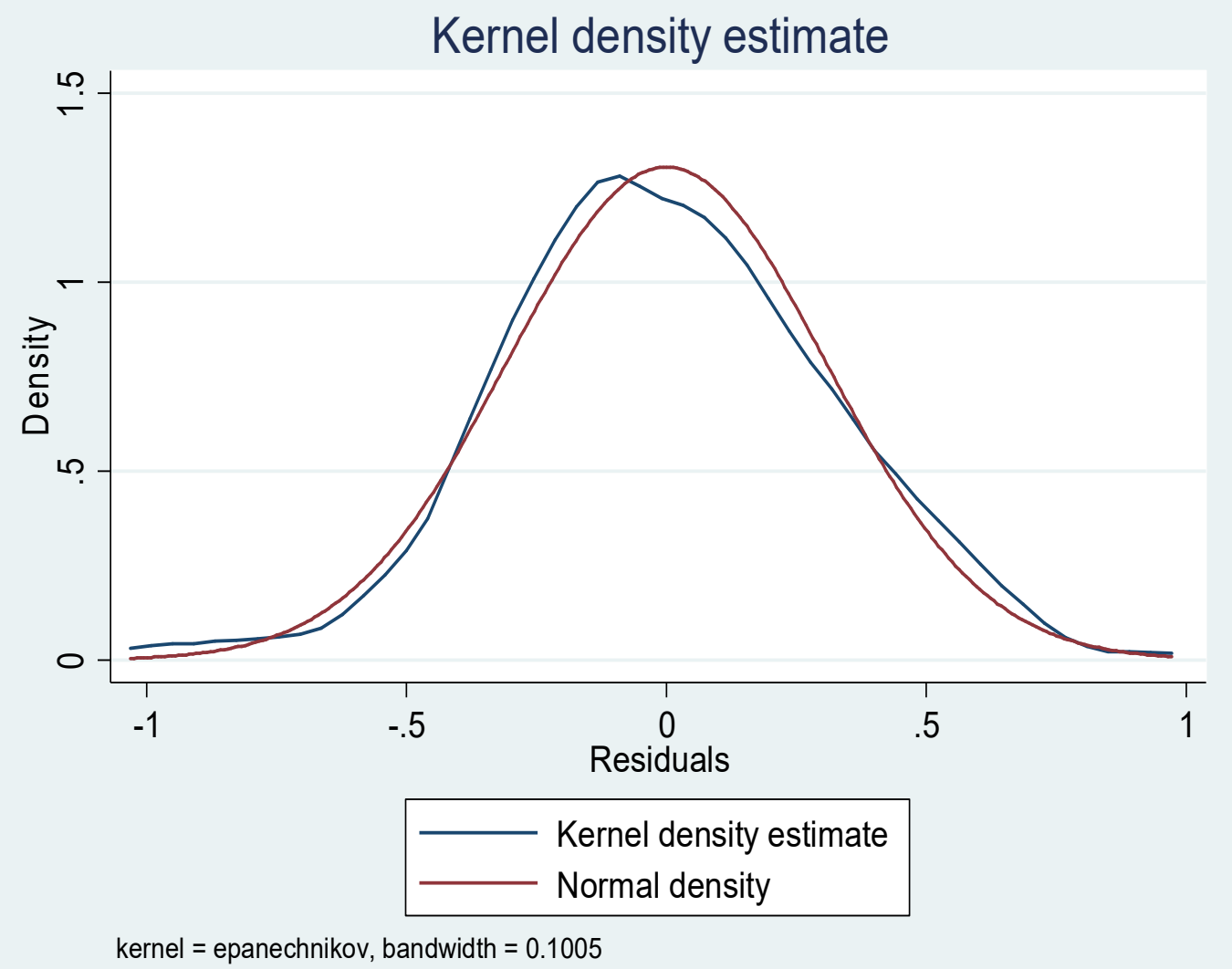

8 The Half -normal probability plot for inefficiency error

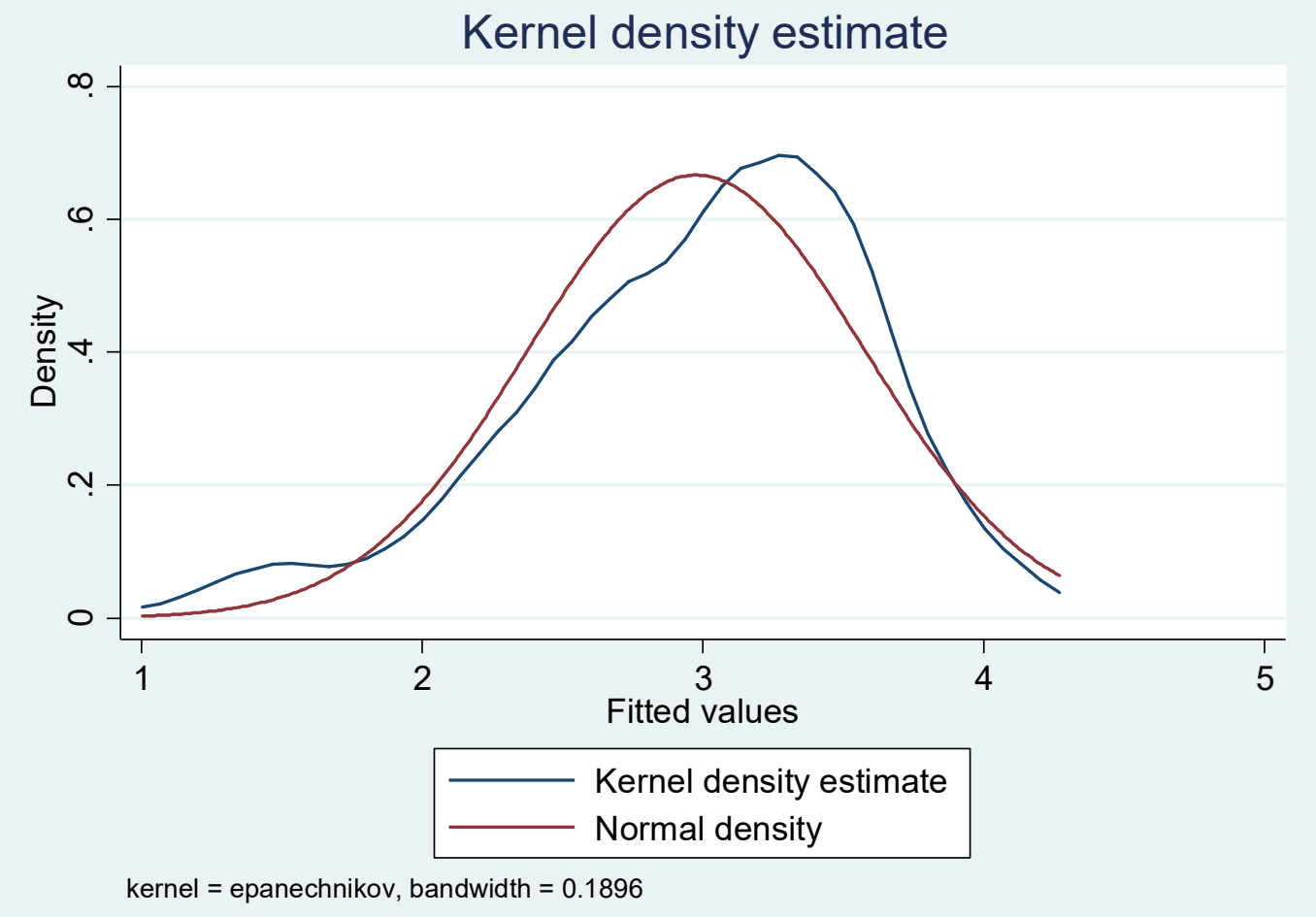

Source: Own computation (2018) 